Research Article

\title{
Spatial Transverse Vibration Simulation Model of Axially Moving Sucker Rod String under the Excitation of Curved Borehole
}

\author{
Hongbo Wang (iD) and Shimin Dong (iD) \\ School of Mechanical Engineering, Yanshan University, Qinhuangdao 066004, China \\ Correspondence should be addressed to Shimin Dong; ysudshm@ysu.edu.cn
}

Received 3 October 2019; Revised 13 May 2020; Accepted 30 June 2020; Published 6 August 2020

Academic Editor: Nicola Nisticò

Copyright (c) 2020 Hongbo Wang and Shimin Dong. This is an open access article distributed under the Creative Commons Attribution License, which permits unrestricted use, distribution, and reproduction in any medium, provided the original work is properly cited.

\begin{abstract}
The mechanical model of transverse vibration of sucker rod string (SRS) in directional well is simplified to the transverse vibration model of longitudinal and transverse curved beam with initial bending under borehole constraints. In this paper, besides considering the excitation of alternating axial load on the transverse vibration of SRS, it is proposed for the first time that curved borehole is also the main excitation for the transverse vibration when the SRS moves reciprocating axially in the borehole. Based on the elastic body vibration theory, the transverse vibration mathematical model of SRS with initial bending under borehole constraints is established. In this model, the curved borehole excitation caused by the axial motion and the alternating axial load excitation is considered. Besides, the elastic collision theory is applied to describe the constraint of tube on the SRS transverse vibration in this model. Then the fourth-order Runge-Kutta method is used to calculate the transverse vibration of SRS in directional wells. The simulation results show the following: (1) The simulation results of the three simulation models in this paper are different. The results indicate that the curved borehole excitation caused by the axial motion and the alternating axial load excitation is the main excitation for the SRS transverse vibration. (2) In directional wells, the rod and tube contact along the well depth, and the dangerous sections locate at the deviation section of the borehole and the compression section of the rod. On the whole, the contact force between rod and tube in deviation section of borehole is larger. The transverse vibration of the compression section of the rod is the most violent.
\end{abstract}

\section{Introduction}

Pumping unit lifting is the main way of artificial lifting [1]. The study of rod string mechanics is the basis of pumping unit lifting design and optimization [2-6]. In oilfields, directional wells account for the vast majority of pumping wells. In directional wells, the inclination and azimuth are always changing, so the slope and torsion are always changing too. The directional borehole trajectory is a space curve with large bending. The bending of borehole trajectory results in large contact force between rod and tube in directional wells, which leads to the irregular wear between rod and tube. The results of oil field production show that the main reasons of directional well overhaul operation are the SRS breakage and tube leakage caused by irregular wear between rod and tube. Therefore, it is of great theoretical and practical significance to study the law of bending deformation of SRS in tube and the simulation method of contact state and rod-tube contact force in directional well.

The bending deformation of SRS in tube is similar to that of drill string in borehole. It can be simplified as a mechanical problem of bending deformation of slender rod string in borehole. At present, there are many researches on the dynamic behavior of drill string [7-15]. Based on different methods and considering different excitation, different transverse vibration simulation models of drill string were established. Yigit and Christoforou [8] established a nonlinear coupling model of torsional and bending vibrations of drill string, considering the rotation of drill string. It was pointed out that the rotational speed of drill string is a main factor affecting the dynamic behavior of drill string. Ghasemloonia et al. [14] established an axial-transverse 
coupling vibration simulation model of drill string, considering the vibration generator tools. The influence of vibration generator tools on the stability and contact behavior of drill string was discussed. In Ghasemloonia et al.'s work [15], considering the mud damping, driving torque, and space alternating axial load excitation, Galerkin's method was used to establish the nonlinear axial-transverse coupling vibration simulation model of rotary drill string. It was proposed that the contact between bottom hole assembly and borehole is the main excitation of drill string transverse vibration in the paper. The dynamic behavior of SRS is studied in [16-21]. Lukasiewicz [18] established an axialtransverse coupling vibration model of SRS in deviation plane based on elastomer theory, considering the initial bending of borehole and the constraint of tube on rod string. $\mathrm{Xu}$ et al. $[19,20]$ established three-dimensional simulation models of axial-transverse coupling vibration of SRS, considering three-dimensional borehole trajectory, turbulent viscous friction, and coulomb friction. Wang et al. [21] established the finite element model of SRS three-dimensional vibration based on the spatial straight beam element. Wang and Dong [22] considered the nonlinear excitation of the SRS's geometric bending stiffness and established the coupled axial-transverse vibration simulation model; then the nonlinear phenomenon of SRS is analyzed on this basis. In pumping wells, the essence of the mechanical model adopted by the above researches can be summarized as follows: The SRS (longitudinal and transverse bending beam) with or without initial bending generates transverse vibration under the excitation of alternating axial load. That is, the alternating axial load is the excitation of transverse vibration of SRS. The essence of transverse vibration excited by alternating axial load is that the alternating axial load leads the SRS's geometric bending stiffness changing with time. It belongs to the nonlinear vibration problem of parametric excitation, and the transverse displacement of SRS is constrained by the tube wall. The intermittent contact collision between the tube wall and SRS is also the excitation of the SRS transverse vibration.

Both the drill string and the SRS have axial motion relative to the borehole. Especially in pumping wells, there is axial reciprocating motion of SRS with large displacement and velocity. As the axial position of the borehole bump acting on the SRS changes with time, the curved borehole trajectory is a transverse vibration excitation for the axially moving SRS. This problem is similar to the dynamic problem of up-down vibration of vehicles under the excitation of rough road surface. At present, the research on transverse vibration of SRS excited by borehole trajectory has not been reported in literature. In this paper, considering the initial bending of SRS caused by the bending of borehole trajectory and considering the excitation of borehole trajectory to the transverse vibration of SRS, a transverse vibration simulation model of SRS in tube is established based on the theory of elastic body vibration.

This paper is organized as follows: In Section 1, the background and research status of the subject are introduced. In Section 2, models for describing borehole trajectory and SRS spatial shape are established. In Section 3, the physical model and mathematical model of rod string transverse are established. In Section 4, the calculating method of the mathematical model of rod string transverse vibration is introduced. In Section 5, a simulation example is calculated, and the simulation results of the three models are compared, which shows the necessity of establishing the model in this paper. Finally the main conclusion is given.

\section{Models for Describing Borehole Trajectory and SRS Spatial Shape}

Figure 1(a) is a schematic diagram of rod, tube, and pump structure of a pumping well. The SRS consists of a certain number of sucker rods and couplings. The SRS can be composed of single-diameter sucker rods or sucker rods with different diameters. In order to reflect the influence of the SRS axial motion on its transverse vibration, the position of any point on the axis of SRS is described by the dynamic position curvilinear coordinates $s$ and the static position curvilinear coordinates $s_{w}$, respectively. The dynamic position curvilinear coordinate is the position of any point on the axis of the SRS relative to the suspension point. The static position curve coordinate is the position of any point on the axis of the SRS relative to the wellhead. Figure 1(b) is a schematic diagram of the borehole trajectory axis and the deformation of rod string axis. The borehole trajectory and the spatial shape of rod string axis can be described by this chart.

\subsection{Spatial Shape Description Model of Borehole Trajectory.} The borehole trajectory is a spatial curve, which can be described in rectangular coordinate system. The Oxyz coordinate system is established with the midpoint of the wellhead as the origin of the coordinate. The directions of unit vectors $\mathbf{i}, \mathbf{j}$, and $\mathbf{k}$ are $x, y$, and $z$, respectively.

Any point A on the borehole trajectory can be expressed as

$$
\mathbf{r}_{\mathrm{A}}\left(s_{w}\right)=x\left(s_{w}\right) \mathbf{i}+y\left(s_{w}\right) \mathbf{j}+z\left(s_{w}\right) \mathbf{k} .
$$

According to the test data of oil well, the inclination angle $\alpha$ and azimuth angle $\varphi$ of the oil well can be obtained. Based on this, tangent vector $\tau_{\mathrm{A}}$, principal normal vector $\mathbf{n}_{\mathrm{A}}$, binormal vector $\mathbf{b}_{\mathrm{A}}$, curvature $k_{\mathrm{A}}$, and torsion $T_{\mathrm{A}}$ at point $\mathrm{A}$ on borehole trajectory axis can be calculated.

The formulas for calculating tangent vector, principal normal vector, and binormal vector are

$$
\left\{\begin{array}{l}
\boldsymbol{\tau}_{\mathrm{A}}=\sin \alpha \cos \varphi \mathbf{i}+\sin \alpha \sin \varphi \mathbf{j}+\cos \alpha \mathbf{k}, \\
\mathbf{n}_{\mathrm{A}}=\frac{1}{k_{\mathrm{A}}} \frac{\partial \tau_{\mathrm{A}}}{\partial s}, \\
\mathbf{b}_{\mathrm{A}}=\boldsymbol{\tau}_{\mathrm{A}} \times \mathbf{n}_{\mathrm{A}},
\end{array}\right.
$$

and the formulas for calculating borehole trajectory axis curvature and torsion are 


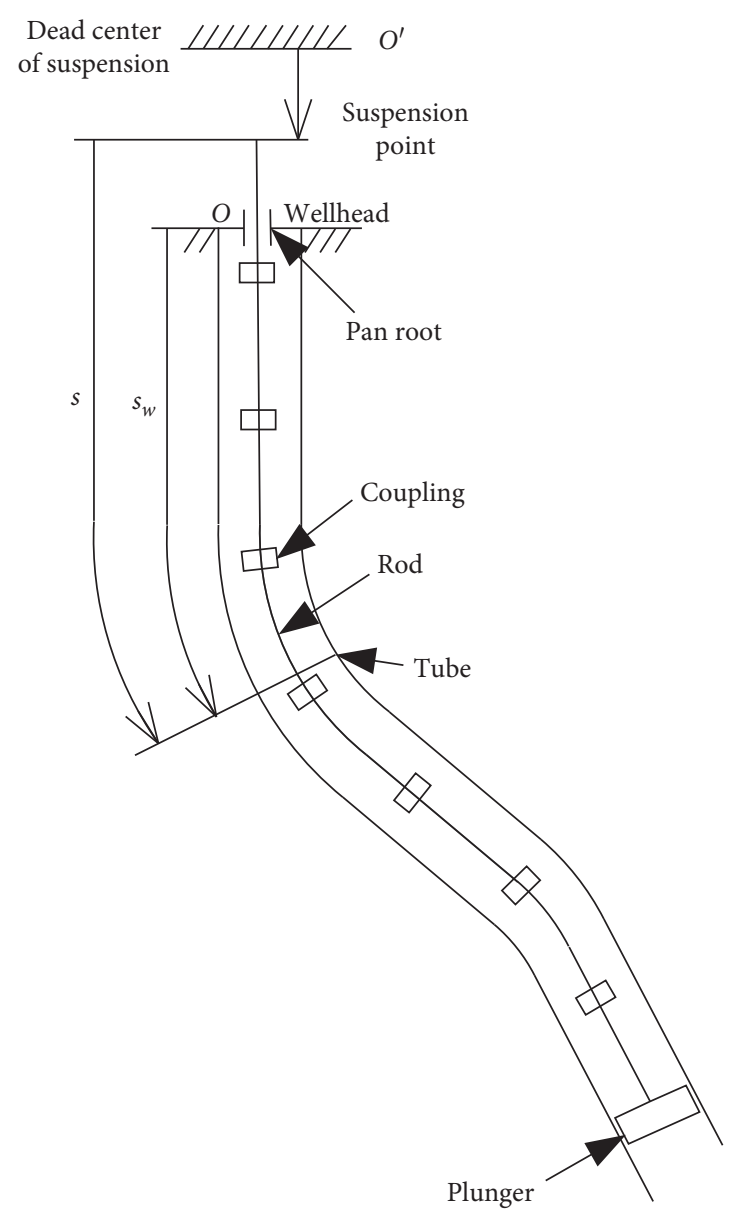

(a)

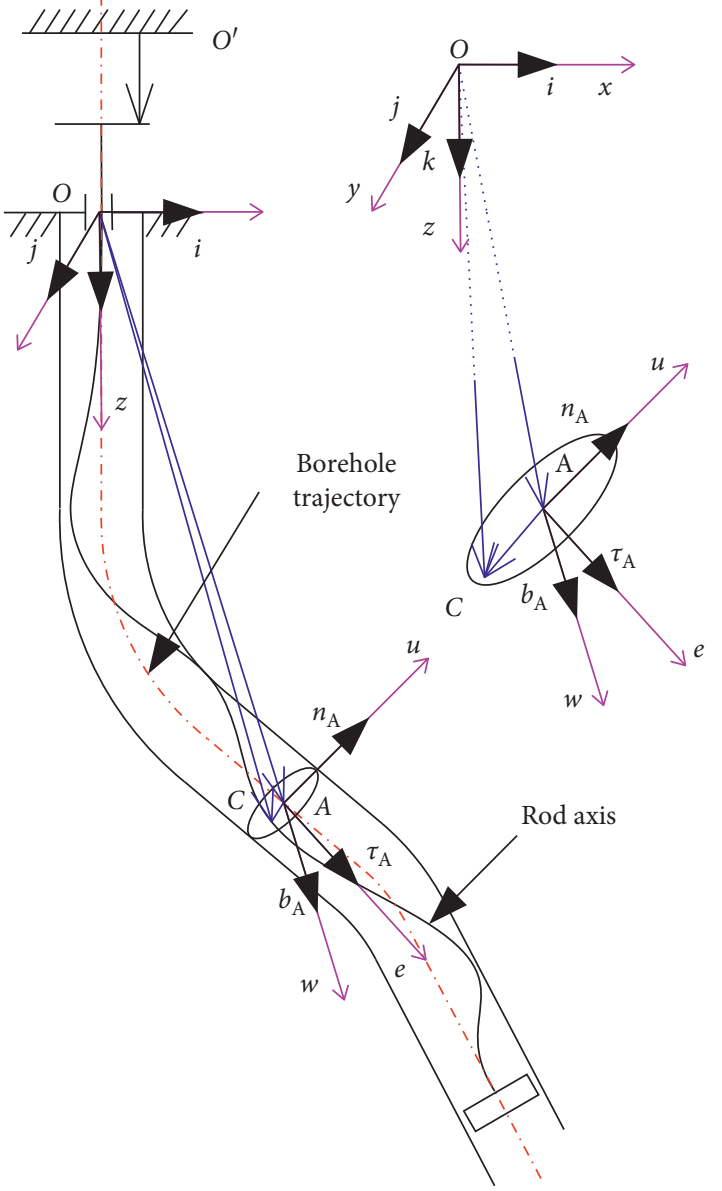

(b)

FIgURE 1: Models for describing borehole trajectory and SRS spatial shape.

$$
\left\{\begin{array}{l}
k_{\mathrm{A}}=\left|\frac{\partial \tau_{\mathrm{A}}}{\partial s_{w}}\right|=\sqrt{\dot{\alpha}^{2}+\dot{\varphi}^{2} \sin ^{2} \alpha}, \\
T_{\mathrm{A}}=\frac{1}{k_{\mathrm{A}}^{2}}\left|\left(\tau_{\mathrm{A}}, \frac{\partial \tau_{\mathrm{A}}}{\partial s_{w}}, \frac{\partial^{2} \tau_{\mathrm{A}}}{\partial s_{w}^{2}}\right)\right| \\
=\frac{1}{k_{\mathrm{A}}^{2}}\left[\begin{array}{c}
\sin \alpha(\dot{\alpha} \ddot{\varphi}-\ddot{\alpha} \dot{\varphi}) \\
+\cos \alpha\left(\dot{\varphi}^{3} \sin ^{2} \alpha \dot{\varphi}^{3}+2 \dot{\alpha}^{2} \dot{\varphi}\right)
\end{array}\right],
\end{array}\right.
$$

where $\dot{\alpha}$ is the first-order derivative of $\alpha$ to $s_{w}$; $\ddot{\alpha}$ is the second-order derivative of $\alpha$ to $s_{w}$; $\dot{\varphi}$ is the first-order derivative of $\varphi$ to $s_{w} ; \ddot{\varphi}$ is the second-order derivative of $\varphi$ to $s_{w}$.

2.2. Spatial Shape Description Model of SRS. Based on the description of borehole trajectory, the new coordinate system is established at the origin of coordinate A point on borehole trajectory, where the direction of $e$ is the same as the tangent direction of point $\mathrm{A}$; the direction of $u$ is the same as the principal normal vector direction of point $\mathrm{A}$; the direction of $w$ is the same as the binormal vector direction of point $\mathrm{A}$. Then point $\mathrm{C}$ of the rod string axis which is corresponding to point $\mathrm{A}$ of borehole trajectory axis can be expressed by $\boldsymbol{r}_{\mathrm{C}}(s)$ :

$$
\mathbf{r}_{\mathrm{C}}(s)=\mathbf{r}_{\mathrm{A}}\left(s_{w}\right)+u(s, t) \mathbf{n}_{\mathrm{A}}+w(s, t) \mathbf{b}_{\mathrm{A}},
$$

where $u(s, t)$ is the displacement of any cross section $s$ of SRS in the direction of principal normal vector at time $t ; w(s, t)$ is the displacement of any cross section $s$ of SRS in the direction of binormal vector at time $t$.

According to Frenet formula, tangent vector $\boldsymbol{\tau}_{\mathrm{C}}(s)$, principal normal vector $\mathbf{n}_{\mathrm{C}}(s)$, binormal vector $\mathbf{b}_{\mathrm{C}}(s)$, curvature $k_{\mathrm{C}}(s)$, and torsion $T_{\mathrm{C}}(s)$ of point C on SRS axis can be calculated.

The formulas for calculating tangent vector, principal normal vector, and binormal vector of point $\mathrm{C}$ on rod string axis can be written as

$$
\left\{\begin{array}{l}
\boldsymbol{\tau}_{\mathrm{C}}=\boldsymbol{\tau}_{\mathrm{A}}+u_{\mathrm{s}} \mathbf{n}_{\mathrm{A}}+w_{\mathrm{s}} \mathbf{b}_{\mathrm{A}}, \\
\mathbf{n}_{\mathrm{C}}=\frac{\left[\left(k_{\mathrm{A}}+u_{\mathrm{ss}}\right) \mathbf{n}_{\mathrm{A}}+w_{\mathrm{ss}} \mathbf{b}_{\mathrm{A}}\right]}{k_{\mathrm{C}}}, \\
\mathbf{b}_{\mathrm{C}}=\frac{\left[-w_{\mathrm{ss}} \mathbf{n}_{\mathrm{A}}+\left(k_{\mathrm{A}}+u_{\mathrm{ss}}\right) \mathbf{b}_{\mathrm{A}}\right]}{k_{\mathrm{C}}},
\end{array}\right.
$$


where $u_{\mathrm{s}}$ is the first-order partial derivative of $u$ to $\mathrm{s} ; u_{\mathrm{ss}}$ is the second-order partial derivative of $u$ to $s ; w_{s}$ is the first-order partial derivative of $w$ to $s$; $w_{s s}$ is the second-order partial derivative of $w$ to s.

The formulas for calculating SRS axis curvature and torsion can be expressed as follows:

$$
\left\{\begin{array}{l}
k_{\mathrm{C}}==\sqrt{\left(k_{\mathrm{A}}+u_{\mathrm{ss}}\right)^{2}+w_{\mathrm{ss}}^{2}}, \\
T_{\mathrm{C}}=\frac{\left\{-w_{\mathrm{ss}}\left[\left(k_{\mathrm{A}}\right)_{\mathrm{s}}+u_{\mathrm{sss}}\right]+w_{\mathrm{sss}}\left[k_{\mathrm{A}}+u_{\mathrm{ss}}\right]\right\}}{k_{\mathrm{C}}^{2}},
\end{array}\right.
$$

where $u_{\mathrm{sss}}$ is the third-order partial derivative of $u$ to $\mathrm{s} ; w_{s s s}$ is the third-order partial derivative of $w$ to $s ;\left(k_{\mathrm{A}}\right)_{\mathrm{s}}$ is the firstorder partial derivative of $k_{\mathrm{A}}$ to $\mathrm{s}$.

\section{Transverse Vibration Mechanics and Mathematical Model}

Figure 1(a) shows that the sucker rod (smooth rod) moves up and down relative to the pan root at the wellhead. The transverse displacement and cross-sectional angle of the SRS are restricted by the pan root. Therefore, while studying the transverse vibration of SRS, the sucker rod at the wellhead pan root can be simplified as a fixed end with axial sliding (ignoring the height of pan root box). The plunger of a sucker rod pump moves up and down in the pump barrel. The transverse displacement and cross-sectional angle of the plunger are restricted by the pump barrel. Therefore, the bottom end of the SRS can also be simplified as a sliding fixed end. The environmental loads on SRS include alternating axial loads acting on the plunger (i.e., the bottom end of the SRS), axial distributed loads, which are related to both time and the axial position of the SRS, and concentrated axial liquid loads acting on each coupling.

In order to facilitate the research and highlight the focus of this paper, the following simplifications and assumptions are made: (1) The rod string is an elastic body, and the rod string moves at the same speed as the suspension point along the borehole trajectory. (2) The rod string is a homogeneous single-stage rod. (3) The influence of longitudinal and torsional vibration of SRS on transverse vibration is not considered. The transverse vibration of SRS is studied only. (4) Do not consider the warping of the cross section of the SRS. The cross section perpendicular to the axis of the SRS before deformation is still perpendicular to the axis of the SRS after deformation. (5) The shear stress of each cross section of the SRS is always in the normal plane of the SRS axis. (6) The centralized axial load acting on the coupling is simplified as the axially distributed load. (7) The position of any point on the axis of SRS is represented by the curvilinear coordinates along the borehole axis.

3.1. Transverse Vibration Equation of SRS. Under the above assumptions, the mechanical model of the SRS transverse vibration shown in Figure 2(a) is established. In the figure, $s$ and $s_{w}$ are, respectively, the dynamic and static position curve coordinates reflecting the position of any point on the axis of suck rod string. $P(t)$ is the axial load acting on the bottom of the SRS at time $t$, with the tension force as the positive direction. $q(s, t)$ or $q\left(s_{w}, t\right)$ is the axial distributed load on the SRS at the axis position $s$ or $s_{w} \cdot q_{u b}(s, t)$ or $q_{u b}\left(s_{w}\right.$, $t$ ) is the transverse distributed load on the SRS at the axis position $s$ or $s_{w}$, that is, the component of the floating weight of the SRS in the direction perpendicular to the axis of the SRS and the liquid resistance of the transverse movement of the SRS. $u_{\mathrm{S}}(t)$ is the displacement of the suspension point relative to the dead center of the suspension at time $t$, and the displacement of the suspension point is positive downward.

Figure 2(b) is the force diagram of the element. The concentrated force at one end of the element can be expressed as the force along the tangential direction, the principal normal direction, and binormal direction of the corresponding borehole trajectory.

Figure 2(c) shows the transverse vibration excitation of the axially moving SRS by the inner wall of the curved tube string (which exaggerates the bending degree of the borehole trajectory in order to clearly show the excitation principle). Assume that point A on SRS is located at point $\mathrm{D}$ on the inner wall of the tube string at time $t$; and the point B on SRS moves to point $\mathrm{D}$ through the $\Delta t$ period. The support point D on the inner wall of the tube string to the supported point on SRS changes with time, which stimulates the transverse vibration of SRS.

The calculation model of the suspension displacement $u_{\mathrm{S}}(t)$ can be established by the kinematic analysis of the mechanism. Based on the longitudinal vibration simulation of SRS, the axial distributed loads $q(s, t)$ and $q\left(s_{w}\right.$, $t)$, transverse distributed loads $q_{u b}(s, t)$ and $q_{u b}\left(s_{w}, t\right)$, and the concentrated axial load $P(t)$ at the bottom of the SRS can be obtained. For the simulation models of $u_{\mathrm{S}}(t), q(s$, $t), q\left(s_{w}, t\right), q_{\mathrm{ub}}(s, t), q_{\mathrm{ub}}\left(s_{w}, t\right)$, and $P(t)$, see literature $[23,24]$, which are not discussed in this paper.

Figure 2(b) is the force diagram of the SRS element. The dynamic equilibrium equation of element can be obtained from the force acting on the element:

$$
F_{e}(s+\mathrm{d} s, t)-F_{e}(s, t)+f_{e}(s, t) \mathrm{d} s=\rho A \frac{\mathrm{d}^{2} U(s, t)}{\mathrm{d} t^{2}} \mathrm{~d} s,
$$

where

$$
\left\{\begin{array}{l}
U(s, t)=e(s, t) \tau_{\mathrm{A}}+u(s, t) \mathbf{n}_{\mathrm{A}}+w(s, t) \mathbf{b}_{\mathrm{A}}, \\
F_{e}(s, t)=F_{e \tau}(s, t) \tau_{\mathrm{A}}+F_{e n}(s, t) \mathbf{n}_{\mathrm{A}}+F_{e b}(s, t) \mathbf{b}_{\mathrm{A}}, \\
F_{e}(s+d s, t)=F_{e}(s, t)+\left(F_{e}\right)_{\mathrm{s}} d s, \\
\left(F_{e}\right)_{\mathrm{s}}=\left[\left(F_{e \tau}\right)_{\mathrm{s}}-k_{\mathrm{A}} F_{e n}\right] \boldsymbol{\tau}_{\mathrm{A}}+\left[F_{e \tau} k_{\mathrm{A}}+\left(F_{e n}\right)_{\mathrm{s}}-F_{e b} T_{\mathrm{A}}\right] \mathbf{n}_{\mathrm{A}} \\
\quad+\left[F_{e n} T_{\mathrm{A}}+\left(F_{e b}\right)_{\mathrm{s}}\right] \mathbf{b}_{\mathrm{A}}, \\
f_{e}(s, t)=f_{e \tau}(s, t) \tau_{\mathrm{A}}+f_{e n}(s, t) \mathbf{n}_{\mathrm{A}}+f_{e b}(s, t) \mathbf{b}_{\mathrm{A}},
\end{array}\right.
$$

where $\rho$ is the density of sucker $\operatorname{rod} A$ is the cross-sectional area of sucker rod; $F_{e \tau}(s, t)$ is the tangential internal force of cross section $s$ on SRS at $t ; F_{e n}(s, t)$ is the internal force of cross section $s$ on SRS at $t$ in the principal normal direction; $F_{e b}(s, t)$ is the internal force of cross section $s$ on SRS at $t$ in the binormal direction; $f_{e \tau}(s, t)$ is the tangential distributed 


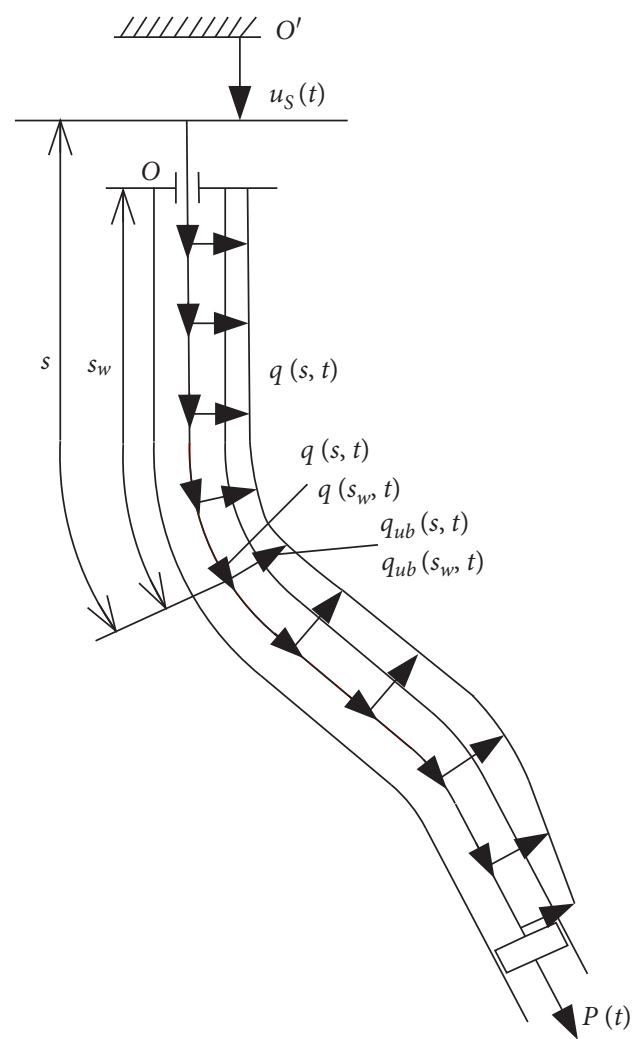

(a)

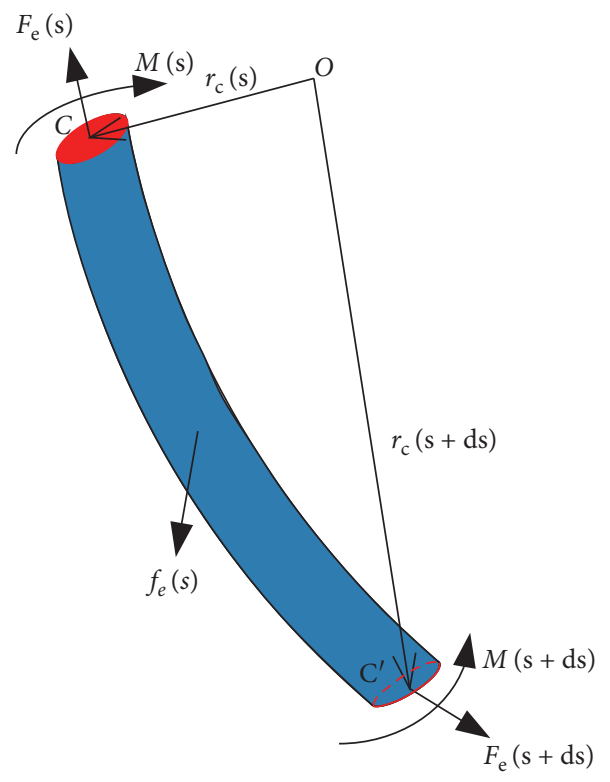

(b)

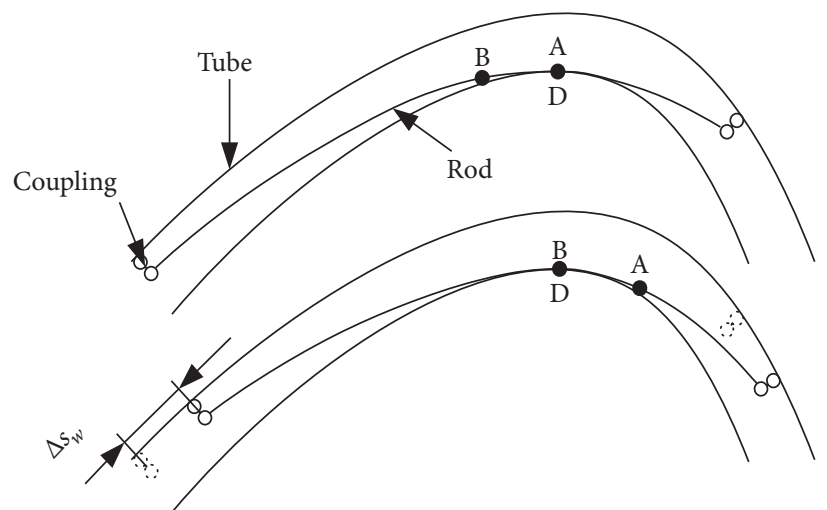

(c)

FIGURE 2: Mechanical model of transverse vibration of SRS. (a) Mechanical model. (b) Element model force. (c) Schematic diagram of borehole trajectory excitation.

external force of cross section $s$ on SRS at $t ; f_{e n}(s, t)$ is the distributed external force of cross section $s$ on SRS at $t$ in the principal normal direction; $f_{e b}(s, t)$ is the distributed external force of cross section $s$ on SRS at $t$ in the binormal direction; $\left(F_{e \tau}\right)_{s}$ is the first-order partial derivative of $F_{e \tau}$ to $s ;\left(F_{e n}\right)_{s}$ is the first-order partial derivative of $F_{e n}$ to $s ;\left(F_{e b}\right)_{s}$ is the firstorder partial derivative of $F_{e b}$ to $s$.

As for the restriction of tube, the transverse vibration of rod string has little effect on the longitudinal vibration, but the longitudinal motion of the rod string will significantly affect its transverse vibration. Therefore, in this paper, the longitudinal vibration of rod string is solved separately through the model established in [23, 24]. Based on the longitudinal vibration simulation results, the transverse vibration is solved; then the axial distributed load of rod string is calculated. Simplifying equation (7), the transverse vibration equilibrium differential equation of rod string in three-dimensional borehole trajectory (model 1) can be obtained:

$$
\left\{\begin{array}{l}
F_{e \tau}(s, t) k_{\mathrm{A}}\left(s_{w}\right)+\frac{\partial F_{e n}(s, t)}{\partial s}-F_{e b}(s, t) T_{\mathrm{A}}\left(s_{w}\right)+f_{e n}(s, t)=\rho A \frac{\mathrm{d}^{2} u(s, t)}{\mathrm{d} t^{2}}, \\
F_{e n}(s, t) T_{\mathrm{A}}\left(s_{w}\right)+\frac{\partial F_{e b}(s, t)}{\partial s}+f_{e b}(s, t)=\rho A \frac{\mathrm{d}^{2} w(s, t)}{\mathrm{d} t^{2}} .
\end{array}\right.
$$

According to the force diagram of the element, the moment balance equation is established. Then the relationship between forces can be obtained: 


$$
\begin{aligned}
& M(s+d s, t)-M(s, t)+\left(r_{\mathrm{C}}(s+d s, t)-r_{\mathrm{C}}(s, t)\right) \\
& \times F_{e}(s+d s, t) \quad+\frac{1}{2}\left(r_{\mathrm{C}}(s+d s, t)-r_{\mathrm{C}}(s, t)\right) \\
& \quad \times f_{e}(s, t) d s=0 .
\end{aligned}
$$

It is simplified to

$$
M_{\mathrm{s}}+\left(F_{e b} u_{\mathrm{s}}-F_{e n} w_{\mathrm{s}}\right) \boldsymbol{\tau}_{\mathrm{A}}+\left(F_{e \tau} w_{\mathrm{s}}-F_{e b}\right) \mathbf{n}_{\mathrm{A}}+\left(F_{e n}-F_{e \tau} u_{\mathrm{s}}\right) \mathbf{b}_{\mathrm{A}}=0,
$$

where

$$
\left\{\begin{array}{l}
M=E I\left(\boldsymbol{\tau}_{\mathrm{C}} \times \frac{\partial \boldsymbol{\tau}_{\mathrm{C}}}{\partial s}\right)=E I k_{\mathrm{C}} b_{\mathrm{C}}, \\
M_{\mathrm{s}}=E I\left(\begin{array}{c}
k_{\mathrm{A}}\left(s_{w}\right) w_{\mathrm{ss}} \boldsymbol{\tau}_{\mathrm{A}}-\left(w_{\mathrm{sss}}+T_{\mathrm{A}}\left(s_{w}\right) k_{\mathrm{A}}\left(s_{w}\right)+T_{\mathrm{A}}\left(s_{w}\right) u_{\mathrm{ss}}\right) \mathbf{n}_{\mathrm{A}} \\
+\left(\left(k_{\mathrm{A}}\left(s_{w}\right)\right)_{\mathrm{s}}+u_{\mathrm{sss}}-T_{\mathrm{A}}\left(s_{w}\right) w_{\mathrm{ss}}\right) \mathbf{b}_{\mathrm{A}}
\end{array}\right),
\end{array}\right.
$$

where $E$ is the elastic model of sucker rod material; $I$ is the bending inertial moment of SRS.

Introducing formulae (12) to (11), $F_{e b}$ and $F_{e n}$ can be obtained:

$$
\left\{\begin{array}{l}
F_{e b}=F_{e \tau} w_{\mathrm{s}}-E I\left(w_{\mathrm{sss}}+T_{\mathrm{A}}\left(s_{w}\right) k_{\mathrm{A}}\left(s_{w}\right)+T_{\mathrm{A}}\left(s_{w}\right) u_{\mathrm{ss}}\right) \\
F_{e n}=F_{e \tau} u_{\mathrm{s}}-E I\left(\left(k_{\mathrm{A}}\left(s_{w}\right)\right)_{\mathrm{s}}+u_{\mathrm{sss}}-T_{\mathrm{A}}\left(s_{w}\right) w_{\mathrm{ss}}\right)
\end{array}\right.
$$

Formula (13)'s partial derivative to $s$ is

$$
\left\{\begin{array}{l}
\left(F_{e b}\right)_{\mathrm{s}}=\left(F_{e \tau}\right)_{\mathrm{s}} w_{\mathrm{s}}+F_{e \tau} w_{\mathrm{ss}}-E I\left(\left(T_{\mathrm{A}}\left(s_{w}\right)\right)_{\mathrm{s}} k_{\mathrm{A}}\left(s_{w}\right)+T_{\mathrm{A}}\left(s_{w}\right)\left(k_{\mathrm{A}}\left(s_{w}\right)\right)_{\mathrm{s}}+w_{\mathrm{ssss}}+\left(T_{\mathrm{A}}\left(s_{w}\right)\right)_{s} u_{\mathrm{ss}}+T_{\mathrm{A}}\left(s_{w}\right) u_{\mathrm{sss}}\right), \\
\left(F_{e n}\right)_{\mathrm{s}}=\left(F_{e \tau}\right)_{\mathrm{s}} u_{\mathrm{s}}+F_{e \tau} u_{\mathrm{ss}}-E I\left(\left(k_{\mathrm{A}}\left(s_{w}\right)\right)_{\mathrm{ss}}+u_{\mathrm{ssss}}-\left(T_{\mathrm{A}}\left(s_{w}\right)\right)_{\mathrm{s}} w_{\mathrm{ss}}-T_{\mathrm{A}}\left(s_{w}\right) w_{\mathrm{sss}}\right),
\end{array}\right.
$$

where $u_{\text {ssss }}$ is the fourth-order partial derivative of $u$ to $s$; $w_{\text {ssss }}$ is the fourth-order partial derivative of $w$ to $s ;\left(T_{\mathrm{A}}\right)_{\mathrm{s}}$ is the first-order partial derivative of $T_{\mathrm{A}}$ to $s ;\left(k_{\mathrm{A}}\right)_{s s}$ is the second-order partial derivative of $k_{\mathrm{A}}$ to $s$.

Distributed external forces acting on rod string can be expressed by the following formula:

$$
\left\{\begin{array}{l}
f_{e n}=-\mu \frac{\mathrm{d} u}{\mathrm{~d} t}-\left(\rho-\rho_{1}\right) g \mathrm{~A} \cos \left\langle\mathbf{n}_{\mathrm{A}}, \mathbf{k}\right\rangle, \\
f_{e b}=-\mu \frac{\mathrm{d} w}{\mathrm{~d} t}-\left(\rho-\rho_{1}\right) g \mathrm{~A} \cos \left\langle\mathbf{b}_{\mathrm{A}}, \mathbf{k}\right\rangle,
\end{array}\right.
$$

where $\rho_{\mathrm{l}}$ is the liquid density in tubing string; $\mu$ is damping coefficient.

The relationship between the static position curvilinear coordinates and the dynamic position curvilinear coordinates of axially moving SRS is as follows:

$$
s_{w}=s-\left(S-u_{\mathrm{S}}(t)\right),
$$

where $S$ is the pumping stroke length.

In order to analyze the effect of curved borehole trajectory excitation on the transverse vibration of axially moving SRS, the comparative simulation model 2 is obtained by ignoring the axial movement of SRS:

$$
\left\{\begin{array}{l}
F_{e \tau}(s, t) k_{\mathrm{A}}(s)+\frac{\partial F_{e n}(s, t)}{\partial s}-F_{e b}(s) T_{\mathrm{A}}(s)+f_{e n}(s, t)=\rho A \frac{\partial^{2} u(s, t)}{\partial t^{2}}, \\
F_{e n}(s, t) T_{\mathrm{A}}(s)+\frac{\partial F_{e b}(s, t)}{\partial s}+f_{e b}(s, t)=\rho A \frac{\partial^{2} w(s, t)}{\partial t^{2}},
\end{array}\right.
$$

where

$$
\left\{\begin{array}{l}
F_{e b}=F_{e \tau} w_{\mathrm{s}}-E I\left(w_{\mathrm{sss}}+T_{\mathrm{A}}(s) u_{\mathrm{ss}}\right), \\
F_{e n}=F_{e \tau} u_{\mathrm{s}}-E I\left(u_{\mathrm{sss}}-T_{\mathrm{A}}(s) w_{\mathrm{ss}}\right), \\
\left(F_{e b}\right)_{\mathrm{s}}=\left(F_{e \tau}\right)_{s} w_{\mathrm{s}}+F_{e \tau} w_{\mathrm{ss}}-E I\left(w_{\mathrm{sss}}+\left(T_{\mathrm{A}}(s)\right)_{\mathrm{s}} u_{\mathrm{ss}}+T_{\mathrm{A}}(s) u_{\mathrm{sss}}\right), \\
\left(F_{e n}\right)_{\mathrm{s}}=\left(F_{e \tau}\right)_{s} u_{\mathrm{s}}+F_{e \tau} u_{\mathrm{ss}}-E I\left(u_{\mathrm{sss}}-\left(T_{\mathrm{A}}(s)\right)_{\mathrm{s}} w_{\mathrm{ss}}-T_{\mathrm{A}}(s) w_{\mathrm{sss}}\right) .
\end{array}\right.
$$

Formulae (9), (13), and (14) can be simplified to the simulation model established in $[18,19]$ (hereinafter referred to as model 3) without considering the geometric stiffness excitation caused by the axial stress and the borehole trajectory excitation caused by the axial motion of SRS:

$$
\left\{\begin{array}{l}
F_{e \tau}(s) k_{\mathrm{A}}+\frac{\partial F_{e n}(s)}{\partial s}-F_{e b}(s) T_{\mathrm{A}}+f_{e n}(s)=\rho A \frac{\partial^{2} u(s, t)}{\partial t^{2}}, \\
F_{e n}(s) T_{\mathrm{A}}+\frac{\partial F_{e b}(s)}{\partial s}+f_{e b}(s)=\rho A \frac{\partial^{2} w(s, t)}{\partial t^{2}}
\end{array}\right.
$$

where

$$
\left\{\begin{array}{l}
F_{e b}=-E I\left(w_{\mathrm{sss}}+T_{\mathrm{A}} u_{\mathrm{ss}}\right), \\
F_{e n}=-E I\left(u_{\mathrm{sss}}-T_{\mathrm{A}} w_{\mathrm{ss}}\right) \\
\left(F_{e b}\right)_{\mathrm{s}}=-E I\left(w_{\mathrm{ssss}}+\left(T_{\mathrm{A}}\right)_{s} u_{\mathrm{ss}}+T_{\mathrm{A}} u_{\mathrm{sss}}\right) \\
\left(F_{e n}\right)_{\mathrm{s}}=-E I\left(u_{\mathrm{sss}}-\left(T_{\mathrm{A}}\right)_{\mathrm{s}} w_{\mathrm{ss}}-T_{\mathrm{A}} w_{\mathrm{sss}}\right) .
\end{array}\right.
$$


3.2. Boundary Condition. SRS is constrained by transverse displacement and angular displacement at the wellhead, so the suspension to the wellhead can be simplified as a sliding fixed constraint. The transverse displacement and angular displacement of the bottom of the rod string are constrained by the pump barrel, so the bottom of the rod string can be simplified as sliding fixed constraints too. The boundary conditions of SRS can be expressed as

$$
\left\{\begin{array}{l}
\left.u\right|_{0 \leq s \leq u_{S}(t)}=0 \\
\left.u\right|_{s=L}=0 \\
\left.\frac{\partial u}{\partial s}\right|_{0 \leq s \leq u_{S}(t)}=0 \\
\left.\frac{\partial u}{\partial s}\right|_{s=L}=0 \\
\left.w\right|_{0 \leq s \leq u_{S}(t)}=0 \\
\left.w\right|_{s=L}=0 \\
\left.\frac{\partial w}{\partial s}\right|_{0 \leq s \leq u_{S}(t)}=0 \\
\left.\frac{\partial w}{\partial s}\right|_{s=L}=0
\end{array}\right.
$$

3.3. Initial Condition. Assuming that the SRS axis coincides with the borehole trajectory axis in the initial state, the suspension point is located at the top dead center. The initial conditions can be expressed as

$$
U(s, 0)=0 ; \frac{\partial U(s, 0)}{\partial t}=0 ; u_{S}(0)=0
$$

3.4. Borehole Restraint. The rod-tube contact force consists of the impact force $F_{s}$ caused by the rod-tube collision and the transverse force $F_{n}$ caused by the bending and axial tension of the rod string.

The rod-rube collision condition is as follows:

$$
\sqrt{u^{2}+w^{2}} \geq R-r_{i}, \quad i=r, c
$$

where $R$ is the inner circle radius of tube; $r_{r}$ is the radius of sucker rod; $r_{c}$ is the radius of coupling; when $i$ takes $r$, it represents the rod string node, and when $i$ takes $c$, it represents the coupling node.

The position of the corresponding node after collision is

$$
\left\{\begin{array}{l}
\left.u\right|_{t+}=\left.\kappa_{n}\left(R-r_{i}\right) \cos \theta_{C}\right|_{t-}, \\
\left.w\right|_{t+}=\left.\kappa_{b}\left(R-r_{i}\right) \sin \theta_{C}\right|_{t-}, \quad i=r, c,
\end{array}\right.
$$

where

$$
\begin{cases}\theta_{C}=\arctan \left(\operatorname{abs}\left(\frac{w}{u}\right)\right), & u_{n} \neq 0, \\ \theta_{C}=\frac{\pi}{2}, & u_{n}=0, \\ \kappa_{n}=\frac{\operatorname{abs}(u)}{u}, & u_{n} \neq 0, \\ \kappa_{b}=\frac{\operatorname{abs}(w)}{w}, & u_{b} \neq 0 .\end{cases}
$$

The velocity of the corresponding nodes after collision is

$$
\left\{\begin{array}{l}
\left.v_{n}\right|_{t+}=\kappa_{n} v_{n A} \cos \theta_{C}+\left.\kappa_{b} v_{\tau A} \sin \theta_{C}\right|_{t+}, \\
\left.v_{b}\right|_{t+}=\kappa_{b} v_{n A} \sin \theta_{C}-\left.\kappa_{n} v_{\tau A} \cos \theta_{C}\right|_{t+},
\end{array}\right.
$$

where

$$
\left\{\begin{array}{l}
\left.v_{\tau A}\right|_{t+}=-\left.\gamma_{s} v_{\tau A}\right|_{t-} ; \\
\left.v_{n A}\right|_{t+}=\left.v_{n A}\right|_{t-}, \\
\left.v_{\tau A}\right|_{t-}=\kappa_{b} v_{n} \sin \theta_{C}-\left.\kappa_{n} v_{b} \cos \theta_{C}\right|_{t-}, \\
\left.v_{n A}\right|_{t-}=\kappa_{n} v_{n} \cos \theta_{C}+\left.\kappa_{b} v_{b} \sin \theta_{C}\right|_{t-}, \\
\left.v_{n}\right|_{t-}=\left.\frac{\mathrm{d} u}{\mathrm{~d} t}\right|_{t-} ; \\
\left.v_{b}\right|_{t-}=\left.\frac{\mathrm{d} w}{\mathrm{~d} t}\right|_{t-},
\end{array}\right.
$$

where $t+$ represents postcollision and $t$ - represent precollision; $\gamma_{s}$ is the collision recovery coefficient, and its value depends on the material of the collision body [25].

As it is difficult to determine the instantaneous value of the collision force, this paper describes the collision force by the change of the impulse. Assuming that the rod-tube collision is completed in $t_{s}$ [26] time period, the distributed force generated by the rod-tube collision in this time period can be calculated by the following formula:

$$
F_{s}=-\left.\frac{\rho A}{t_{s}}\left(1+\gamma_{s}\right) v_{n O}\right|_{t-}
$$

The formula for calculating the transverse force of rod string is

$$
F_{n}=\kappa_{n}\left(\begin{array}{c}
F_{e \tau} k_{0}+\left(F_{e n}\right)_{s}-F_{e b} T_{0} \\
-\left(\rho-\rho_{l}\right) g A \cos n
\end{array}\right) \cos \theta_{s}+\kappa_{b}\left(\begin{array}{c}
F_{e n} T_{0}+\left(F_{e b}\right)_{s} \\
-\left(\rho-\rho_{l}\right) g A \cos b
\end{array}\right) \sin \theta_{s} .
$$

The rod-tube contact force can be expressed as

$$
F_{t}=F_{s}+F_{n} .
$$




\section{Transverse Vibration Simulation Method}

The simulation model of the transverse vibration of SRS is a fourth-order partial differential equation with variable coefficients, so the analytical solution of the equation cannot be obtained. Therefore, the fourth-order Runge-Kutta method is used to solve the problem. The solution forms are as follows:

$$
\left\{\begin{array}{l}
\mathrm{d} y(1)=y(2) \\
\mathrm{d} y(2)=F_{e \tau}(s, t) k_{\mathrm{A}}\left(s_{w}\right)+\frac{\partial F_{e n}(s, t)}{\partial s}-F_{e b}(s, t) T_{\mathrm{A}}\left(s_{w}\right) \\
\quad+f_{e n}(s, t) \\
\mathrm{d} y(3)=y(4) \\
\mathrm{d} y(4)=F_{e n}(s, t) T_{\mathrm{A}}\left(s_{w}\right)+\frac{\partial F_{e b}(s, t)}{\partial s}+f_{e b}(s, t)
\end{array}\right.
$$

where $y(1)$ represents $u ; y(2)$ represents $v_{n} ; y(3)$ represents $w$; $y(4)$ represents $v_{b}$.

The initial condition of the formula is

$$
y=[0,0,0,0]^{T} \text {. }
$$

Combining with the borehole constraints in Section 3.4, equation (31) can be solved by adding the corresponding discriminant conditions in the solution process. Then the simulation results of the transverse vibration of SRS in curved borehole can be obtained. Figure 3 is a flow chart for calculating transverse vibration of rod string.

\section{Simulation Example and Simulation Analysis}

5.1. Basic Parameters. Basic simulation parameters are as follows: rod column diameter is $22 \mathrm{~mm}$; coupling diameter is $46 \mathrm{~mm}$; rod string length is $1305 \mathrm{~m}$; rod string density is $7800 \mathrm{~kg} / \mathrm{m}^{3}$; elastic modulus of rod string is $210 \mathrm{GPa}$; inner diameter of tube is $62 \mathrm{~mm}$; stroke length of pumping unit is $6 \mathrm{~m}$; stroke frequency of pumping unit is $6 \mathrm{~min}^{-1}$. The borehole trajectory, suspension point motion law, and axial force of SRS are shown in Figure 4. Observing Figure 4(a), it is found that the deviation sections of the borehole are near $400 \mathrm{~m}$ and $1100 \mathrm{~m}$, respectively.

5.2. Simulation Results. Based on the above three simulation models, the transverse vibration simulation system of SRS in directional well is developed. The transverse vibration law of SRS and the contact force between rod and tube are obtained. Figure 5 shows the simulation results obtained by model 1. In Table 1, the characteristic values of the rod-tube contact force in one cycle are counted. Through observation, it is found that the average contact forces obtained by the three models are similar. However, the maximum value of the rod-tube contact force and the position and time of the maximum value are not the same. The standard deviation of the difference between contact force simulation results obtained by model 2 , model 3 , and model 1 can reach $17.72 \mathrm{~N} / \mathrm{m}$ and $56.10 \mathrm{~N} / \mathrm{m}$, respectively, which indicates that the simulation results of the instantaneous contact force obtained by the three models are quite different (the smaller the standard deviation is, the more similar the simulation results are). The rod-tube contact force is related to the vibration law of SRS, so the simulation results of the three models are different. In the following, the simulation results at the same time and the simulation results of same nodes are analyzed in Sections 5.2.1 and 5.2.2, respectively.

5.2.1. Simulation Results at the Same Time. Figure 4(c) shows that the axial force of the SRS is always changing. The calculation nodes of SRS are always under tension at $3 \mathrm{~s}$; a part of the calculation nodes at the bottom of the SRS are under compression at $9 \mathrm{~s}$. To reflect the influence of axial force on the transverse vibration of SRS, the transverse vibration simulation results of the SRS at $3 \mathrm{~s}$ and $9 \mathrm{~s}$ are analyzed. Figure 6 shows the simulation results of the coupling node at $3 \mathrm{~s}$; Figure 7 shows the simulation results of the rod node at $3 \mathrm{~s}$; Figure 8 shows the simulation results of the coupling node at $9 \mathrm{~s}$; Figure 9 shows the simulation results of the rod node at 9 s. Table 2 is the statistical table of the coupling nodes and sucker rods, which contact with tube string at $3 \mathrm{~s}$ and $9 \mathrm{~s}$. Table 3 is the statistical table of rod-tube contact force characteristic values at $3 \mathrm{~s}$ and $9 \mathrm{~s}$.

Figure 6(a) and Table 2 show that most of the coupling nodes on SRS contact with the tube string at $3 \mathrm{~s}$. The contact state of SRS and tube string obtained by the three models is obviously different at $0 \sim 100 \mathrm{~m}$ and $1100 \sim 1305 \mathrm{~m}$. There are 115 coupling nodes contacting with tube string in the simulation results of model 1, 106 coupling nodes contacting with tube string in the simulation results of model 2 , and 125 coupling nodes contacting with tube string in the simulation results of model 3 at $3 \mathrm{~s}$. In the simulation results of model 1 and model 2, there are 37 coupling nodes with different contact states, accounting for $25.7 \%$ of the total coupling nodes. In the simulation results of model 1 and model 3, there are 42 coupling nodes with different contact states, accounting for $29.2 \%$ of the total coupling nodes. From the observation of Figure 6(b) and Table 3, it can be found that there are obvious differences in the simulation results of rodtube contact force. Generally, the contact forces of most coupling nodes obtained by model 1 and model 2 are larger than that obtained by model 3. The average contact forces obtained by model 1 and model 2 are significantly larger than that obtained by model 3. Although the average contact forces obtained by model 1 and model 2 are similar (the difference is $1.97 \mathrm{~N} / \mathrm{m}$ ), the standard deviation of the difference between the simulation results obtained by model 2 and model 1 is as high as $74.31 \mathrm{~N} / \mathrm{m}$, which shows that the distribution law of rod-tube contact forces obtained by model 1 and model 2 is also different at $3 \mathrm{~s}$. It can be found that the contact forces of coupling nodes near the deviation section of the borehole are relatively larger, and the node with the largest contact force locates at the first deviation section (the deviation section nearest to wellhead). 


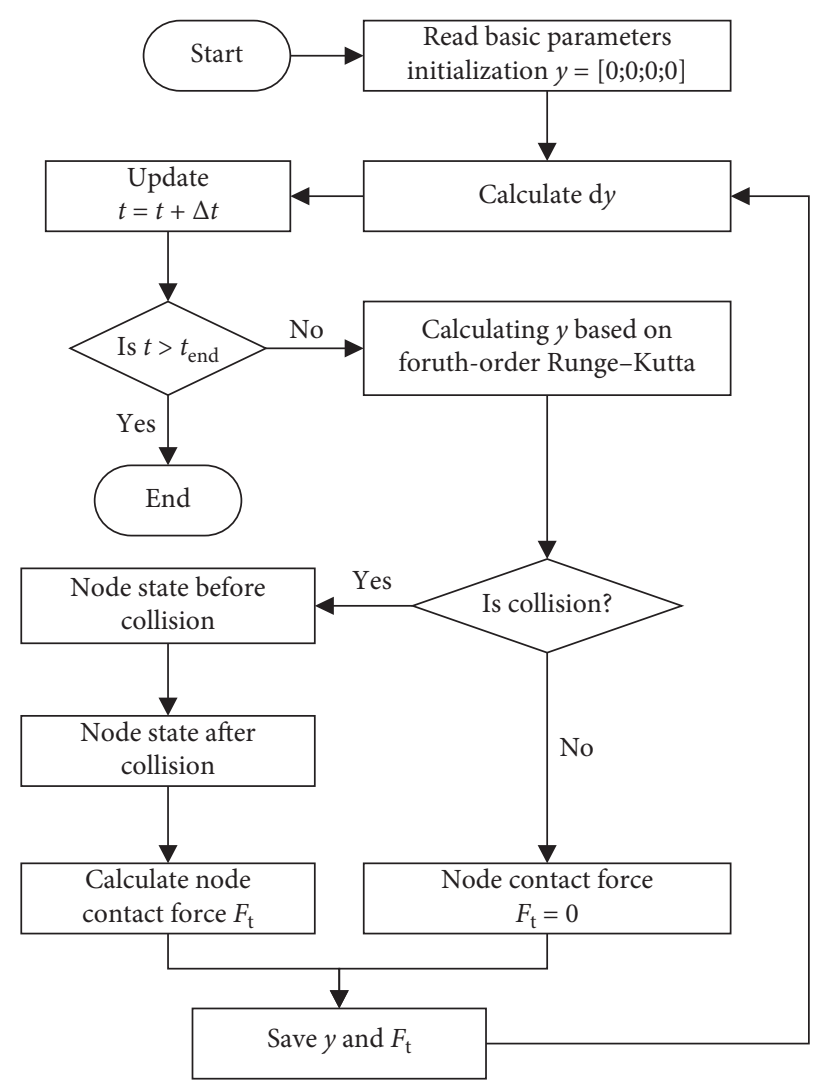

Figure 3: Computational flow chart.

Through the observation of Figure 7 (a) and Table 2, it can be found that the contact nodes of model 1 and model 2 mainly locate at the deviation sections of the borehole at $3 \mathrm{~s}$, while the contact nodes of model 3 appear from the first deviation section of the borehole to the bottom of SRS. In the simulation results of model 1 and model 2, there are 4 sucker rods with different contact states, accounting for $2.8 \%$ of the total sucker rods. According to Figure 7(a), it can be seen that the specific contact rod nodes of the sucker rods with the same contact state are not exactly the same. In the simulation results of model 1 and model 3, there are 80 sucker rods with different contact states, accounting for $55.2 \%$ of the total sucker rods. Observing Figure 7(b), it is found that there are significant differences between the three models' simulation results of rod-tube contact force. In combination with $\mathrm{Ta}-$ ble 3, it can be known that the contact force of the coupling node is larger than that of the rod node. The average contact forces obtained by model 1 and model 2 are smaller than that obtained by model 3 at $3 \mathrm{~s}$. Although the average contact forces obtained by model 1 and model 2 are similar (the difference is $0.01 \mathrm{~N} / \mathrm{m}$ ), the standard deviation of the difference between the simulation results obtained by model 2 and model 1 is $2.25 \mathrm{~N} / \mathrm{m}$, which is larger than the average contact force. The above phenomenon shows that the distribution laws of the rod nodes contact force obtained by model 1 and model 2 are also different at $3 \mathrm{~s}$.

Figure 8 (a) shows that most of the coupling nodes on SRS contact with the tube at $9 \mathrm{~s}$. According to Table 2, it can be found that, in the simulation results of model 1 and model
2 , there are 39 coupling nodes with different contact states, accounting for $27.1 \%$ of the total coupling nodes. In the simulation results of model 1 and model 3, there are 37 coupling nodes with different contact states, accounting for $25.7 \%$ of the total coupling nodes. The contact state obtained by the three models is obviously different at $0 \sim 300 \mathrm{~m}$. Figure $8(\mathrm{~b})$ and Table 3 show that the values of rod-tube contact force obtained by the three models are different too at $9 \mathrm{~s}$. The average contact forces obtained by model 1 and model 2 are larger than that of model 3 at $9 \mathrm{~s}$. The average contact force difference between model 1 and model 2 is $5.36 \mathrm{~N} / \mathrm{m}(3.5 \%)$, and the standard deviation of the difference between the simulation results obtained by model 2 and model 1 is $48.22 \mathrm{~N} / \mathrm{m}$, which shows that the coupling nodes simulation results obtained by model 1 and model 2 are different too at $9 \mathrm{~s}$. Likewise, the contact force of the coupling node at the first deviation section is larger too at $9 \mathrm{~s}$. However, different form the simulation results at $3 \mathrm{~s}$, the rod-tube contact force of coupling node in the deviation section near to the rod string bottom is not significantly higher than that of other coupling nodes at $9 \mathrm{~s}$.

Figure 9(a) shows that there are always contact nodes on the SRS, from the first deviation section to the bottom of the SRS. According to Table 2, it is found that, in the simulation results of model 1 and model 2 , there are 14 sucker rods with different contact states, accounting for $9.7 \%$ of the total sucker rods. In the simulation results of model 1 and model 3 , there are 58 sucker rods with different contact states, accounting for $40.0 \%$ of the total sucker rods. According to 


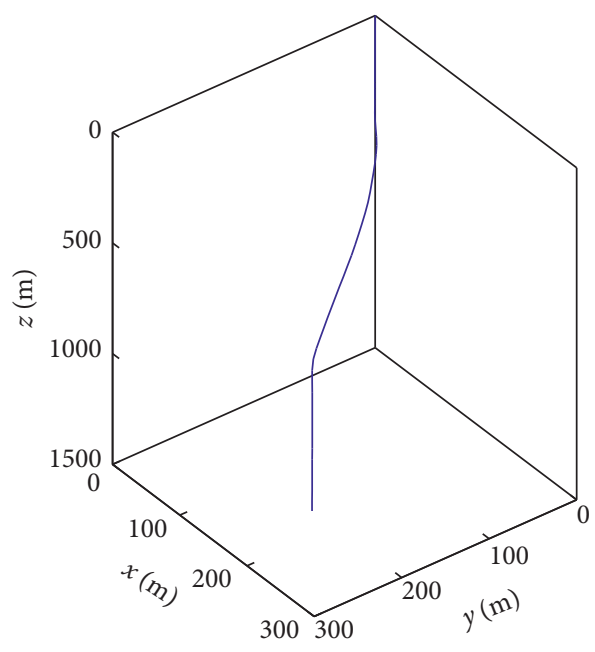

(a)

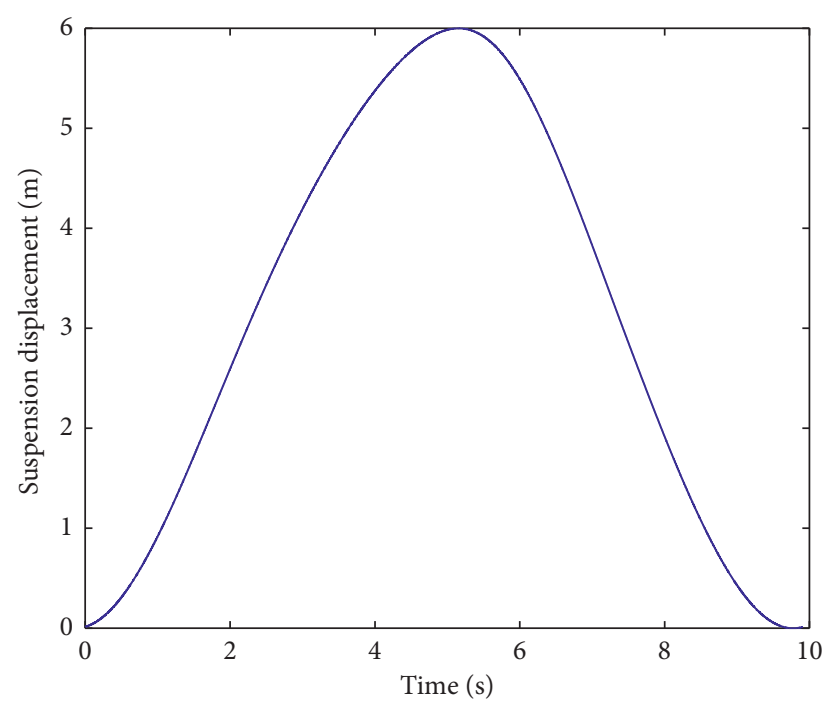

(b)

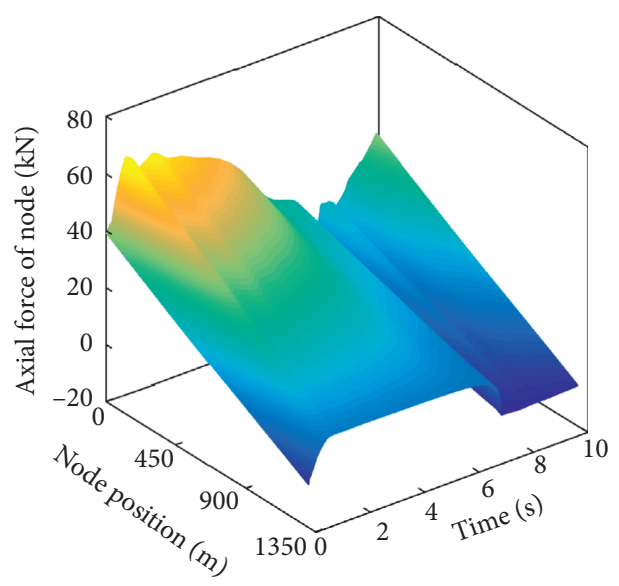

(c)

Figure 4: Curves of well trajectory, suspension displacement, and axial stress. (a) Borehole trajectory. (b) Suspension displacement. (c) Axial force of node.

Table 3, it can be known that the average contact forces obtained by model 1 and model 2 are smaller than that obtained by model 3 at $9 \mathrm{~s}$. The standard deviation of the difference between the simulation results obtained by model 2 and model 1 is $12.86 \mathrm{~N} / \mathrm{m}$. It shows that the rod nodes contact forces obtained by model 1 and model 2 are different at $9 \mathrm{~s}$. Observation of Figure 9(b) shows that the maximum rod-tube contact force of the rod node obtained by model 1 and model 2 appears in the compression section at the bottom of SRS.

From the above observations, the following can be found: (1) At the same time, the contact state and the distribution law of the contact force obtained by the three models are different. (2) The simulation results of the three models show that the transverse vibrations of SRS obtained by model 1 and model 2 are more obvious. (3) Most of the coupling nodes on the SRS contact with the tube in the whole well, and the contact force is much larger than that of the rod node.
5.2.2. Simulation Results of the Same Node. In this section, the simulation results of the two coupling nodes at $531 \mathrm{~m}$ and $1080 \mathrm{~m}$ are compared; and the simulation results of the two rod nodes at $500 \mathrm{~m}$ and $1283 \mathrm{~m}$ are compared. Combining with Figure 4, it can be seen that nodes at $500 \mathrm{~m}$ and $531 \mathrm{~m}$ are near to the first deviation section of the borehole, and the nodes are under tension during the whole pumping process. The nodes at $1080 \mathrm{~m}$ and $1283 \mathrm{~m}$ are near to the deviation section near to the bottom of SRS, and the nodes are under compression during a period of time in the whole pumping process. Figure 10 shows the simulation results of the coupling node at $531 \mathrm{~m}$; Figure 11 shows the simulation results of the coupling node at $1080 \mathrm{~m}$; Figure 12 shows the simulation results of the rod node at $500 \mathrm{~m}$; Figure 13 shows the simulation results of the rod node at $1283 \mathrm{~m}$. Table 4 is the statistical table of contact force characteristic values of the above four simulation nodes in one cycle.

According to Figures 10 and 11 and Table 4, the following phenomena were found: (1) The average contact 


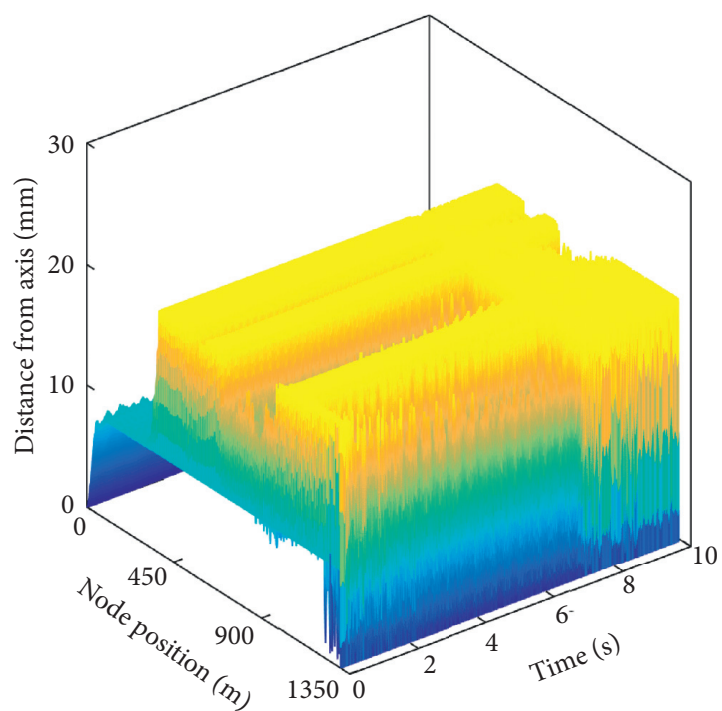

(a)

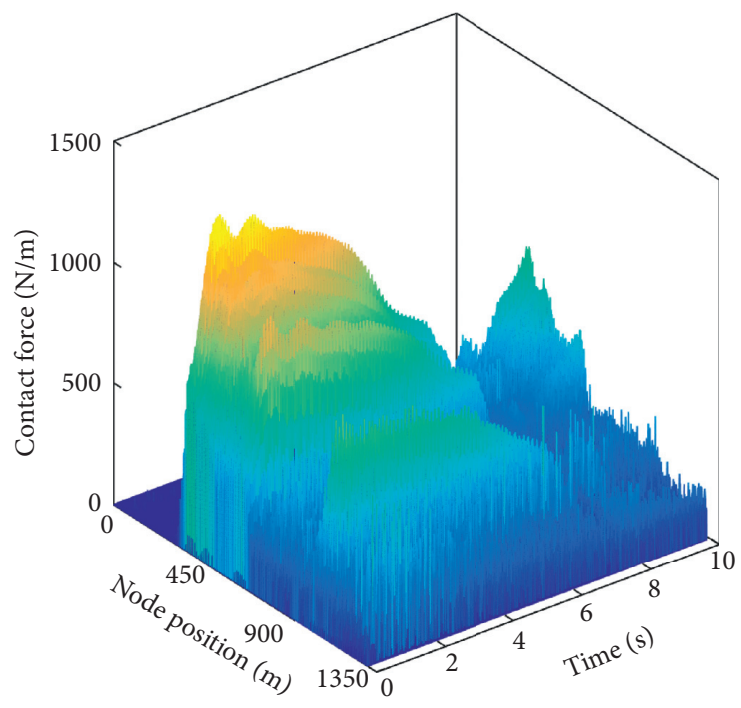

(b)

FiguRE 5: Simulation results of model 1. (a) Distance between the node position and the borehole axis. (b) Contact force between rod and tube.

TABLE 1: Statistical table of rod-tube contact force characteristic values in one cycle.

\begin{tabular}{lccccc}
\hline Model & $\begin{array}{c}\text { Average contact } \\
\text { force }(\mathrm{N} / \mathrm{m})\end{array}$ & $\begin{array}{c}\text { Position of max contact } \\
\text { force }(\mathrm{m})\end{array}$ & $\begin{array}{c}\text { Time of max contact } \\
\text { force }(\mathrm{s})\end{array}$ & $\begin{array}{c}\text { The max contact } \\
\text { force }(\mathrm{N} / \mathrm{m})\end{array}$ & $\begin{array}{c}\text { Standard deviation of difference } \\
\text { with model } 1(\mathrm{~N} / \mathrm{m})\end{array}$ \\
\hline $\begin{array}{l}\text { Model } \\
1\end{array}$ & 14.91 & 405 & $0.807 \mathrm{~s}$ & 1361.1 & 1370.2 \\
$\begin{array}{l}\text { Model } \\
2\end{array}$ & 14.99 & 396 & $0.798 \mathrm{~s}$ & 536.1 & 56.10 \\
$\begin{array}{l}\text { Model } \\
3\end{array}$ & 14.76 & 386 & $0.762 \mathrm{~s}$ & 536 \\
\hline
\end{tabular}

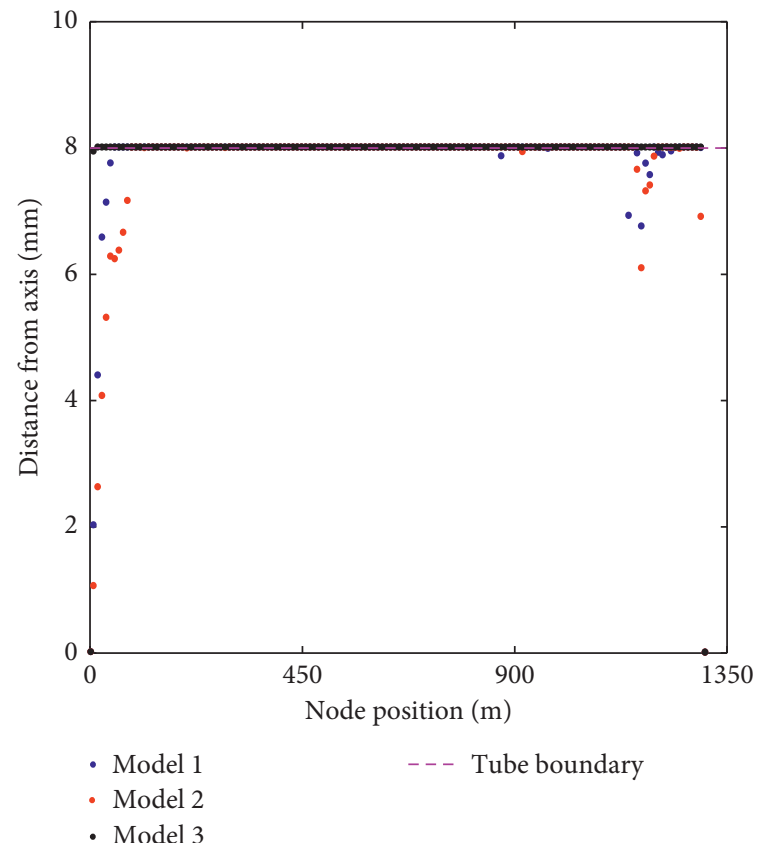

(a)

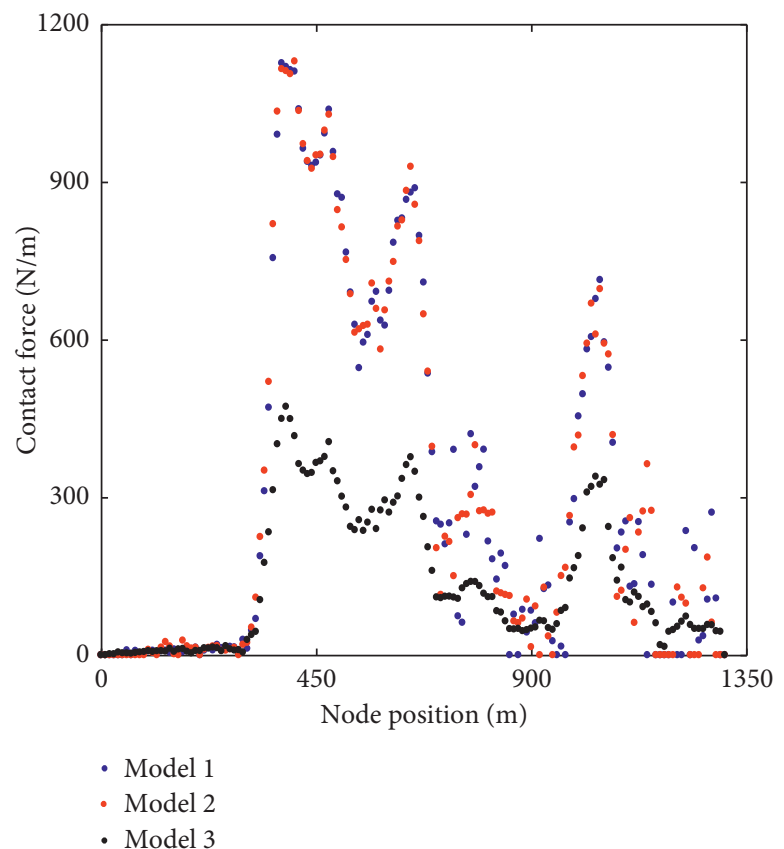

(b)

Figure 6: The coupling node simulation results at $3 \mathrm{~s}$. (a) Distance between node position and borehole axis. (b) Contact force between rod and tube. 


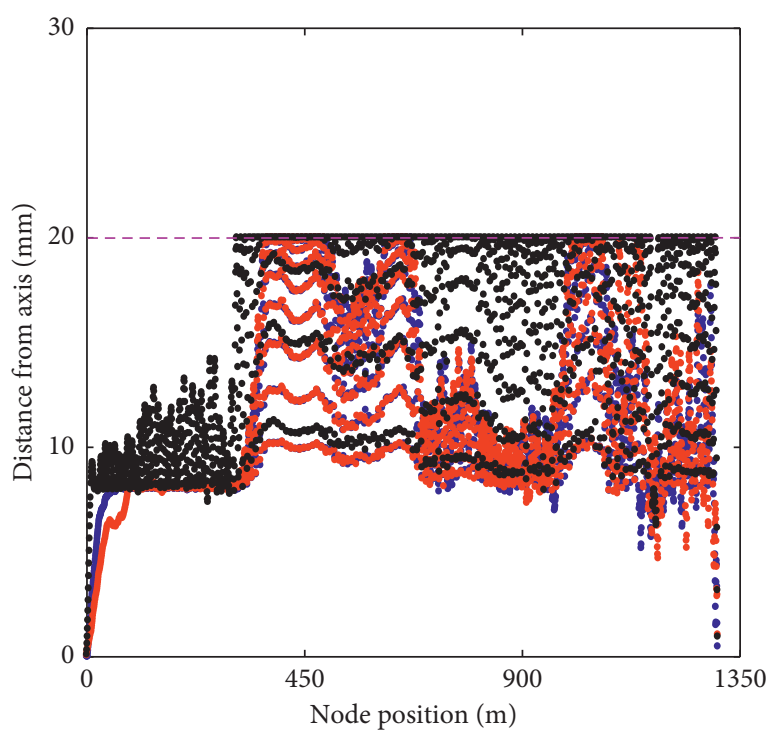

- Model 1

- Model 2

- Model 3

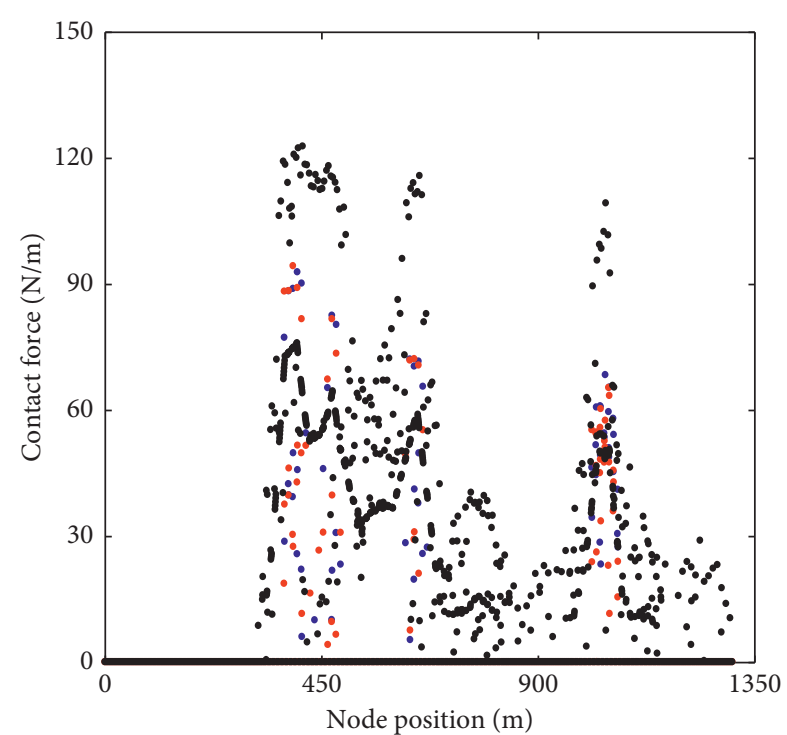

- Model 1

- Model 2

- Model 3

(a)

(b)

Figure 7: The rod node simulation results at $3 \mathrm{~s}$. (a) Distance between node position and borehole axis. (b) Contact force between rod and tube.

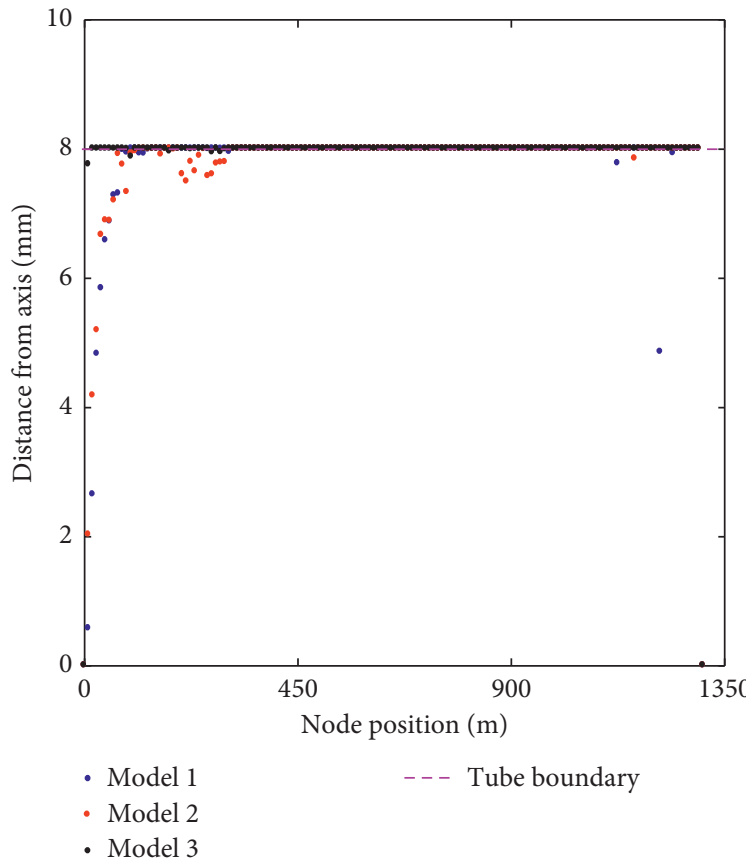

(a)

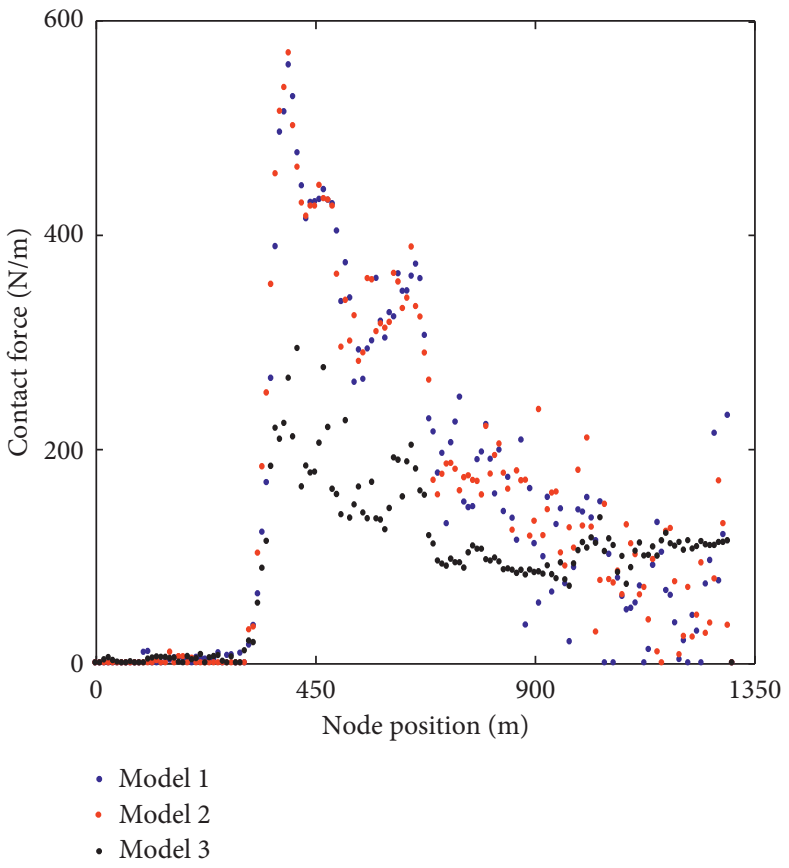

(b)

Figure 8: The coupling node simulation results at $9 \mathrm{~s}$. (a) Distance between node position and borehole axis. (b) Contact force between the rod and tube.

forces obtained by model 1 and model 2 are similar at $531 \mathrm{~m}$ and $1080 \mathrm{~m}$, but the standard deviations of the difference between the simulation results obtained by model 2 and model 1 are $51.80 \mathrm{~N} / \mathrm{m}$ and $103.55 \mathrm{~N} / \mathrm{m}$, respectively; the average contact forces obtained by model 1 and model 3 are obviously different, and the standard deviation is huge too, 


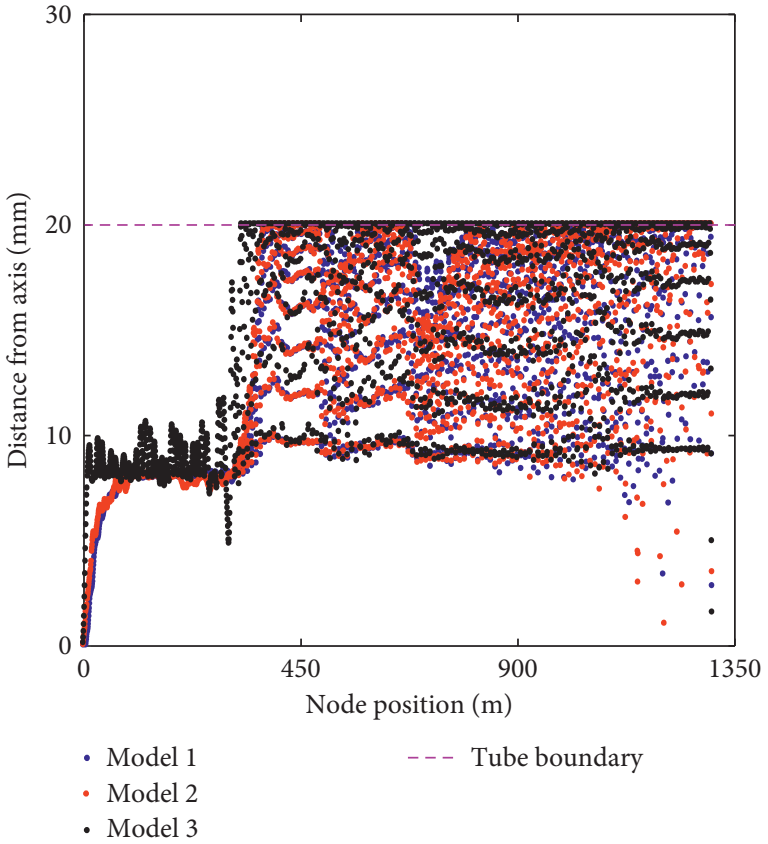

(a)

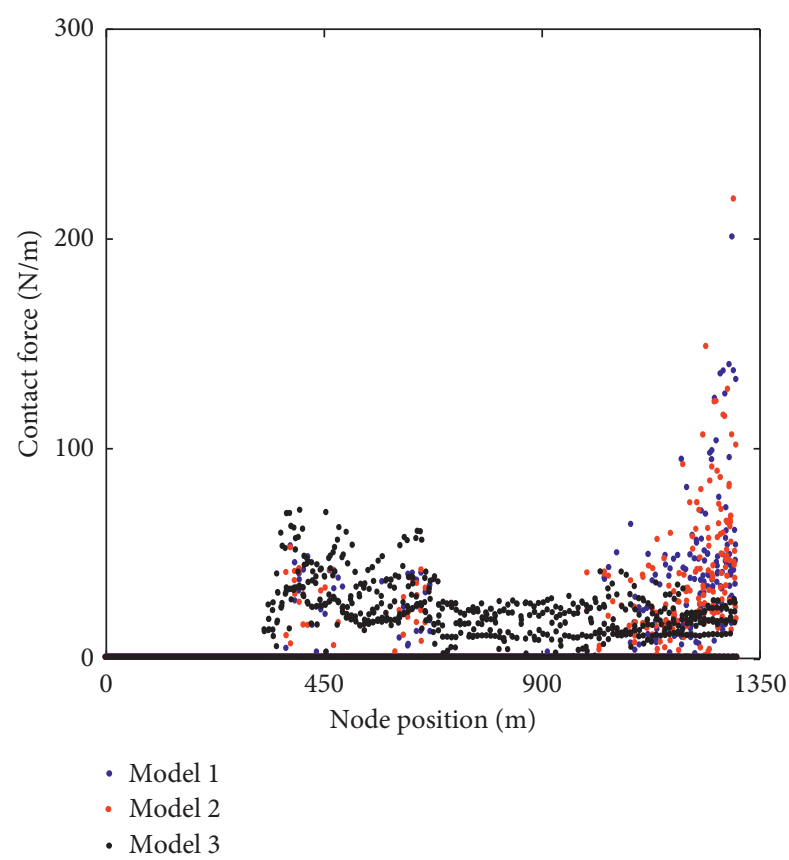

(b)

Figure 9: The rod node simulation results at $9 \mathrm{~s}$. (a) Distance between node position and borehole axis. (b) Contact force between the rod and tube.

TABLE 2: Statistical table of the coupling nodes and sucker rods, which contact with tube string at $3 \mathrm{~s}$ and $9 \mathrm{~s}$.

\begin{tabular}{|c|c|c|c|}
\hline $\begin{array}{l}\text { Time } \\
(\mathrm{s})\end{array}$ & Type & Model & The coupling nodes/sucker rods contact with tube string \\
\hline \multirow{6}{*}{3} & \multirow{3}{*}{$\begin{array}{l}\text { Coupling } \\
\text { node }\end{array}$} & Model 1 & $6,8 \sim 11,14 \sim 22,24 \sim 34,36,37,41 \sim 47,49 \sim 92,94 \sim 96,99 \sim 105,107,109 \sim 126,128,133,136,139 \sim 143$ \\
\hline & & Model 2 & $12,14,15,17 \sim 22,24,27,29 \sim 31,33 \sim 71,75 \sim 77,80 \sim 101,103,104,106 \sim 123,125 \sim 128,134 \sim 136,141$ \\
\hline & & Model 3 & $\begin{array}{c}2 \sim 8,10 \sim 16,18 \sim 29,32,33,35 \sim 37,39 \sim 43,46 \sim 59,61 \sim 64,68 \sim 74,76 \sim 99,101 \sim 104,106 \sim 115,117 \sim 125 \text {, } \\
127 \sim 136,138 \sim 144\end{array}$ \\
\hline & \multirow{3}{*}{ Sucker rod } & Model 1 & $42 \sim 47,49,51 \sim 55,70 \sim 75,113 \sim 119$ \\
\hline & & Model 2 & $42 \sim 48,50 \sim 55,70 \sim 74,113 \sim 119$ \\
\hline & & Model 3 & $36 \sim 129,134 \sim 137,139 \sim 145$ \\
\hline \multirow{6}{*}{9} & \multirow{3}{*}{$\begin{array}{l}\text { Coupling } \\
\text { node }\end{array}$} & Model 1 & $\begin{array}{c}11,12,17 \sim 21,23 \sim 28,31,33,35 \sim 42,44 \sim 56,58 \sim 66,68,72 \sim 74,76 \sim 78,80,81,83 \sim 106,108 \sim 111,113 \sim 115, \\
117 \sim 124,126 \sim 131,133,134,136,137,139 \sim 144\end{array}$ \\
\hline & & Model 2 & $14,17,19,20,22,36 \sim 40,42 \sim 44,47 \sim 49,52 \sim 69,71,73 \sim 118,120 \sim 128,131 \sim 134,136 \sim 138,140 \sim 144$ \\
\hline & & Model 3 & $\begin{array}{c}2 \sim 5,8,12 \sim 19,21 \sim 24,26 \sim 29,34 \sim 37,39 \sim 47,49 \sim 56,58 \sim 74,76 \sim 102,104 \sim 107,109 \sim 129,131 \sim 141 \\
143 \sim 144\end{array}$ \\
\hline & \multirow{3}{*}{ Sucker rod } & Model 1 & $42 \sim 48,51 \sim 55,68 \sim 75,77,111,113,115,116,118,121 \sim 145$ \\
\hline & & Model 2 & $42 \sim 47,50 \sim 55,57,69 \sim 74,92,106,111,114 \sim 119,121,122,124 \sim 127,129 \sim 145$ \\
\hline & & Model 3 & $37 \sim 145$ \\
\hline
\end{tabular}

indicating that the simulation results of instantaneous contact forces obtained by the three models are different. (2) The simulation results obtained by the three models show that the coupling node at $531 \mathrm{~m}$ is always in contact with the tube. The simulation results of the coupling node at $1080 \mathrm{~m}$ obtained by model 1 and model 2 show that there exists transverse vibration at the $1080 \mathrm{~m}$ coupling node. Combining with Figure $4(\mathrm{c})$, it can be seen that the vibration mainly occurs in the compression period.

By observing Figures 12 and 13 and Table 4, the following can be found: (1) The simulation results obtained by the three models in the same period are different for the same rod node. Although the average contact forces obtained by model 1 and model 2 are similar at $500 \mathrm{~m}$ and $1283 \mathrm{~m}$, the standard deviations of the difference between the simulation results obtained by model 2 and model 1 are $3.54 \mathrm{~N} / \mathrm{m}$ and $18.96 \mathrm{~N} / \mathrm{m}$, respectively. It shows that the instantaneous contact forces obtained by the two models are obviously different. (2) The simulation results obtained by model 1 and model 2 show that the transverse vibration of the rod node is relatively obvious. (3) The transverse vibration of the rod node at $1283 \mathrm{~m}$ is more obvious than that 
TABLE 3: Statistical table of rod-tube contact force characteristic values at $3 \mathrm{~s}$ and $9 \mathrm{~s}$.

\begin{tabular}{|c|c|c|c|c|c|c|}
\hline $\begin{array}{l}\text { Time } \\
(\mathrm{s})\end{array}$ & Node type & Model & $\begin{array}{l}\text { Average contact } \\
\text { force }(\mathrm{N} / \mathrm{m}) \\
\end{array}$ & $\begin{array}{l}\text { Position of max contact } \\
\text { force }(\mathrm{m})\end{array}$ & $\begin{array}{l}\text { The max contact } \\
\text { force }(\mathrm{N} / \mathrm{m})\end{array}$ & $\begin{array}{c}\text { Standard deviation of difference } \\
\text { with model } 1(\mathrm{~N} / \mathrm{m})\end{array}$ \\
\hline \multirow{6}{*}{3} & \multirow{3}{*}{$\begin{array}{l}\text { Coupling } \\
\text { node }\end{array}$} & $\begin{array}{c}\text { Model } \\
1\end{array}$ & 319.13 & 378 & 1126.0 & \\
\hline & & $\begin{array}{c}\text { Model } \\
2\end{array}$ & 321.10 & 405 & 1129.4 & 74.31 \\
\hline & & $\begin{array}{c}\text { Model } \\
3\end{array}$ & 141.61 & 387 & 472.6 & 223.83 \\
\hline & \multirow{3}{*}{ Rod node } & $\begin{array}{c}\text { Model } \\
1\end{array}$ & 1.17 & 500.5 & 92.79 & \\
\hline & & $\begin{array}{c}\text { Model } \\
2\end{array}$ & 1.16 & 391.5 & 94.25 & 2.25 \\
\hline & & $\begin{array}{c}\text { Model } \\
3\end{array}$ & 11.77 & 411.5 & 122.73 & 23.20 \\
\hline \multirow{6}{*}{9} & \multirow{3}{*}{$\begin{array}{l}\text { Coupling } \\
\text { node }\end{array}$} & $\begin{array}{c}\text { Model } \\
1\end{array}$ & 152.70 & 396 & 560.80 & \\
\hline & & $\begin{array}{c}\text { Model } \\
2\end{array}$ & 158.06 & 396 & 573.03 & 48.22 \\
\hline & & $\begin{array}{c}\text { Model } \\
3\end{array}$ & 95.80 & 414 & 293.04 & 98.83 \\
\hline & \multirow{3}{*}{ Rod node } & $\begin{array}{c}\text { Model } \\
1\end{array}$ & 3.02 & 1294.5 & 196.75 & \\
\hline & & $\begin{array}{c}\text { Model } \\
2\end{array}$ & 3.06 & 1297.5 & 217.97 & 12.86 \\
\hline & & $\begin{array}{c}\text { Model } \\
3\end{array}$ & 5.49 & 375 & 69.61 & 16.67 \\
\hline
\end{tabular}

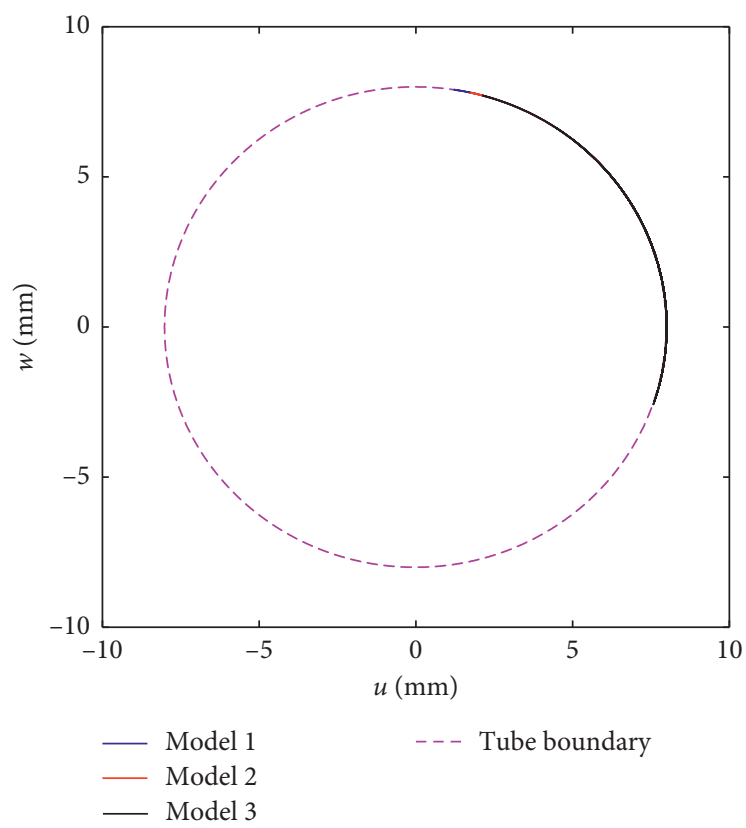

(a)

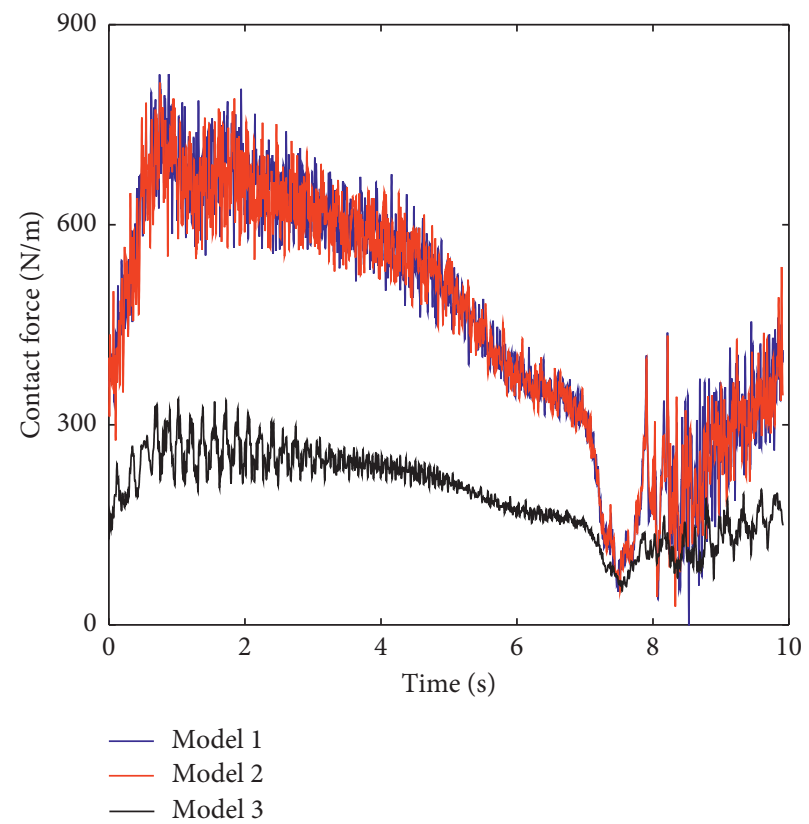

(b)

Figure 10: Simulation results of the coupling node at $531 \mathrm{~m}$. (a) Node position. (b) Contact force between the rod and tube.

at $500 \mathrm{~m}$, and the rod-tube contact force is larger (the difference is $15.35 \mathrm{~N} / \mathrm{m}$ ).

From the above observations, the following can be found: (1) In the same period, the instantaneous contact states and the contact forces obtained by the three models are different. (2) Compared with the tension section, the transverse vibration is more obvious in the compression section, and the contact force is larger. (3) Compared with the rod node, the rod-tube contact force of coupling node is larger.

Through the analysis of Sections 5.2.1 and 5.2.2, the following conclusions can be obtained: (1) The simulation 


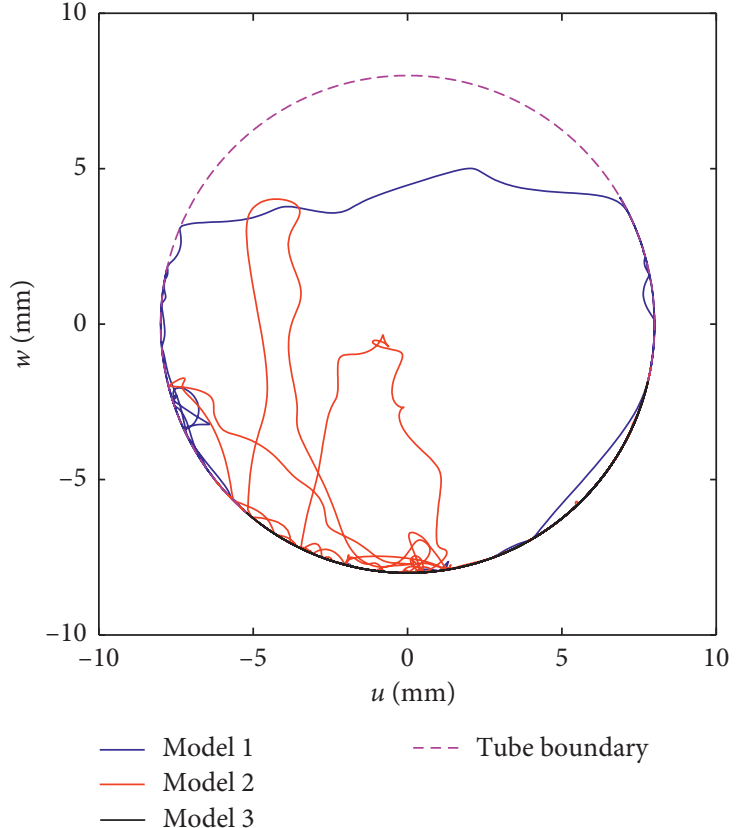

(a)

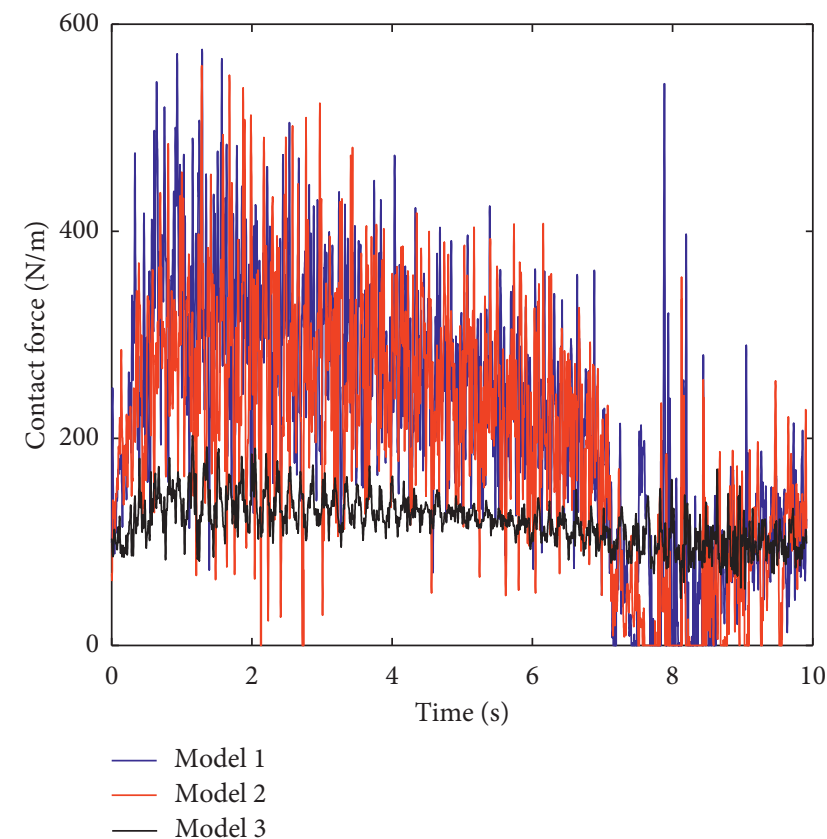

(b)

FIgURE 11: Simulation results of the coupling node at $1080 \mathrm{~m}$. (a) Node position. (b) Contact force between the rod and tube.

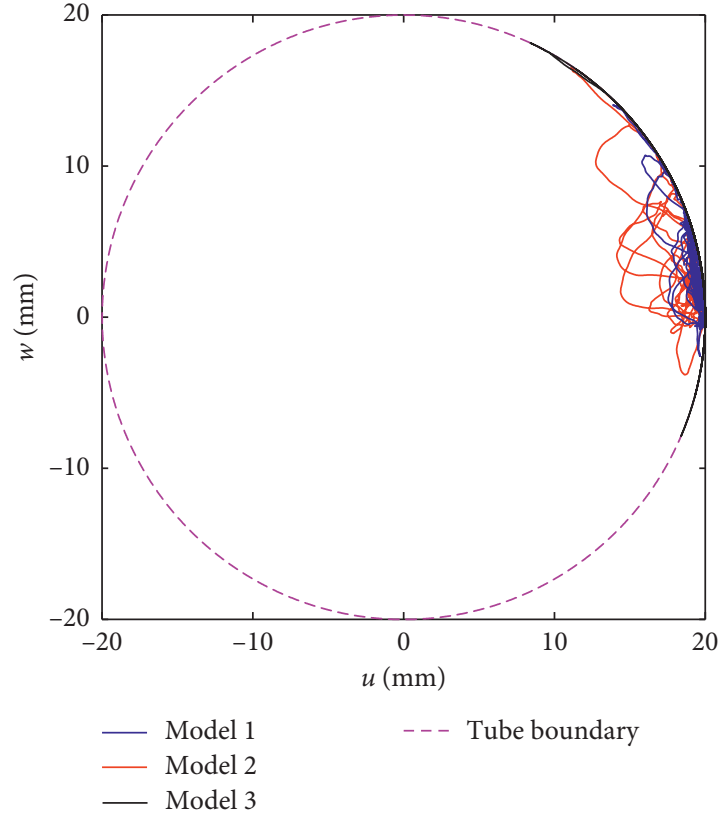

(a)

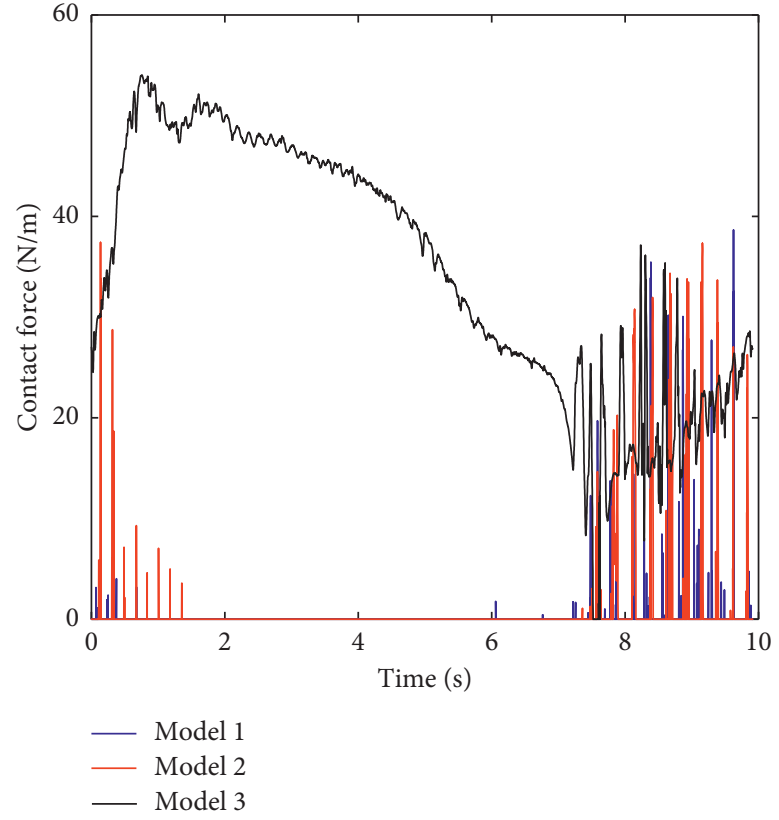

(b)

FIGURE 12: Simulation results of the rod node at $500 \mathrm{~m}$. (a) Node position. (b) Contact force between the rod and tube.

results of the instantaneous contact states and the instantaneous contact forces obtained by the three models are different. The simulation results obtained by model 1 and model 2 show that the transverse vibration of rod string is more obvious, which indicates that the transverse vibration of the rod string will be intensified by the borehole trajectory excitation caused by the axial motion of the rod string and the geometric stiffness excitation caused by the axial force. (2) Compared with the tension section, the transverse vibration of rod string in the compression section is more obvious, which indicates that the transverse vibration rigidity of the rod string is strengthened when the rod string is under tension, and the transverse vibration rigidity of the rod string is weakened when the rod string is compressed. 


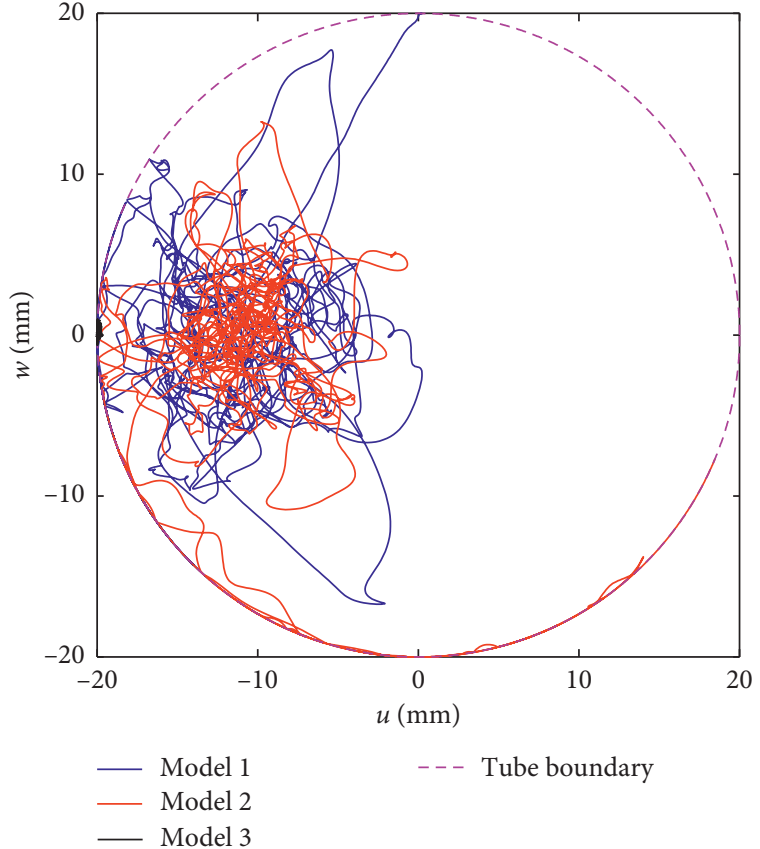

(a)

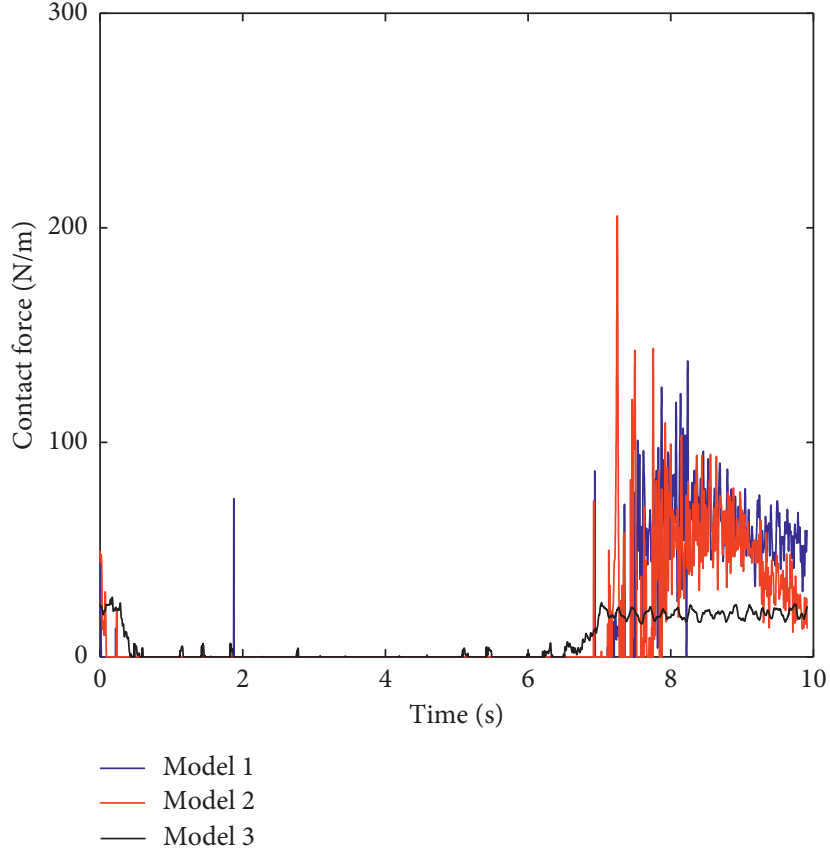

(b)

Figure 13: Simulation results of the rod node at $1283 \mathrm{~m}$. (a) Node position. (b) Contact force between the rod and tube.

TABLE 4: Statistical table of rod-tube contact force characteristic values of specific nodes in one cycle.

\begin{tabular}{|c|c|c|c|c|c|c|}
\hline Node type & $\begin{array}{l}\text { Position } \\
(\mathrm{m})\end{array}$ & Model & $\begin{array}{l}\text { Average contact } \\
\text { force }(\mathrm{N} / \mathrm{m})\end{array}$ & $\begin{array}{l}\text { Time of max contact } \\
\text { force }(\mathrm{s})\end{array}$ & $\begin{array}{l}\text { The max contact } \\
\text { force }(\mathrm{N} / \mathrm{m})\end{array}$ & $\begin{array}{c}\text { Standard deviation of difference } \\
\text { with model } 1(\mathrm{~N} / \mathrm{m})\end{array}$ \\
\hline \multirow{6}{*}{$\begin{array}{l}\text { Coupling } \\
\text { node }\end{array}$} & \multirow{3}{*}{531} & $\begin{array}{c}\text { Model } \\
1\end{array}$ & 459.97 & 0.879 & 826.0 & \\
\hline & & $\begin{array}{c}\text { Model } \\
2\end{array}$ & 455.65 & 0.750 & 813.2 & 51.80 \\
\hline & & $\begin{array}{c}\text { Model } \\
3\end{array}$ & 195.99 & 1.022 & 339.0 & 131.50 \\
\hline & \multirow{3}{*}{1080} & $\begin{array}{c}\text { Model } \\
1\end{array}$ & 221.40 & 1.290 & 575.8 & \\
\hline & & $\begin{array}{c}\text { Model } \\
2\end{array}$ & 199.49 & 1.283 & 560.1 & 103.55 \\
\hline & & $\begin{array}{c}\text { Model } \\
3\end{array}$ & 119.69 & 1.152 & 202.8 & 105.75 \\
\hline \multirow{6}{*}{ Rod node } & \multirow{3}{*}{500} & $\begin{array}{c}\text { Model } \\
1\end{array}$ & 0.13 & 9.625 & 38.7 & \\
\hline & & $\begin{array}{c}\text { Model } \\
2\end{array}$ & 0.51 & 0.136 & 37.4 & 3.54 \\
\hline & & $\begin{array}{c}\text { Model } \\
3\end{array}$ & 34.50 & 0.757 & 54.0 & 13.09 \\
\hline & \multirow{3}{*}{1283} & $\begin{array}{c}\text { Model } \\
1\end{array}$ & 15.48 & 8.236 & 138.0 & \\
\hline & & $\begin{array}{c}\text { Model } \\
2\end{array}$ & 12.38 & 7.250 & 205.4 & 18.96 \\
\hline & & $\begin{array}{c}\text { Model } \\
3\end{array}$ & 7.25 & 0.170 & 27.9 & 21.84 \\
\hline
\end{tabular}

(3) The contact force between rod and tube in the deviation section of borehole is larger, which indicates that the deviation section in directional well is the dangerous section of the rod-tube eccentric wear. (4) The transverse vibration of the compression section of rod string is the most obvious. It shows that the compression section of rod string in directional well is also the dangerous section of the rod-tube eccentric wear. (5) The contact force between rod and tube is affected by many factors. The simulation model 1 of the SRS transverse vibration established in this paper is more comprehensive and suitable for the prediction of wear position and wear life of SRS. 


\section{Conclusions}

According to the above researches, the following conclusions can be obtained:

(1) The transverse vibration of SRS is one of the main factors leading to eccentric wear between SRS and tube string, so the research on SRS transverse vibration has always been the focus in oil field. In this paper, based on the previous studies (model 3), the transverse vibration simulation model 2 of SRS is established considering the geometric stiffness excitation caused by the alternating axial force. On the basis of model 2, it is proposed that the curved borehole trajectory is a main excitation of the SRS transverse vibration, and a more comprehensive transverse vibration simulation model 1 of SRS is established. Then the fourth-order Runge-Kutta method is used to simulate the transverse vibration of SRS in directional wells. The simulation results show that the dangerous section of eccentric wear between SRS and tube string occurs in the deviation section of oil well and the compression section of SRS. The rod-tube contact force is relatively larger in the deviation section of oil well, and the transverse vibration of SRS is relatively obvious in the compressed section of SRS.

(2) Through the above quantitative and qualitative analysis, it is found that although the average contact forces between SRS and tube string obtained by the three models are similar in the whole cycle, the change rules of the instantaneous contact state and instantaneous contact force between SRS and tube string are different. It shows that the main excitation of SRS transverse vibration includes the geometric stiffness excitation caused by the alternating axial force and the curved borehole trajectory excitation caused by the SRS axial movement. So the transverse vibration simulation model 1 is more comprehensive.

(3) The simulation of the instantaneous contact position and contact force between SRS and tube string is the basis of the prediction of the eccentric wear position and the wear life of SRS. According to the research results of this paper, it is found that the geometric stiffness excitation caused by the alternating axial force and the curved borehole trajectory excitation caused by the SRS axial movement will significantly affect the simulation results of the instantaneous contact position and contact force between SRS and tube string. Therefore, the transverse vibration simulation model 1 of SRS established in this paper is helpful to predict the eccentric wear position and the wear life of SRS more accurately, and it is of great significance and economic value to prevent eccentric wear of SRS.

\section{Data Availability}

The data used to support the findings of this study are included within the article.

\section{Conflicts of Interest}

The authors declare that there are no conflicts of interest regarding the publication of this paper.

\section{Acknowledgments}

This work was supported by the National Natural Science Foundation of China (51974276).

\section{References}

[1] H. Liu, Z. Hao, L. Wang et al., "Current technical status and development trend of artificial lift," Acta Petrolei Sinica, vol. 36, no. 11, pp. 1441-1448, 2015.

[2] M. Xing, "Response analysis of longitudinal vibration of sucker rod string considering rod buckling," Advances in Engineering Software, vol. 99, pp. 49-58, 2016.

[3] S. Mohammad and N. Amir Zayeri Baghlani, "Numerical analysis of free longitudinal vibration of nonuniform rods: discrete singular convolution approach," Journal of Engineering Mechanics, vol. 140, no. 8, Article ID 06014007, 2014.

[4] X. Sun, S. Dong, M. Liu et al., "The simulation model of sucker rod string transverse vibration under the space buckling deformation excitation and rod-tubing eccentric wear in vertical wells," Journal of Vibroengineering, vol. 20, no. 1, pp. 283-299, 2018.

[5] Q. Zhang, B. Jiang, W. Huang, W. Cui, and J. Liu, "Effect of wellhead tension on buckling load of tubular strings in vertical wells," Journal of Petroleum Science and Engineering, vol. 164, pp. 351-361, 2018.

[6] B. Zhang, X. Gao, and X. Li, "Diagnosis of sucker rod pump based on generating dynamometer cards," Journal of Process Control, vol. 77, pp. 76-88, 2019.

[7] A. S. Yigit and A. P. Christoforou, "Coupled axial and transverse vibrations of oilwell drillstrings," Journal of Sound and Vibration, vol. 195, no. 4, pp. 617-627, 1996.

[8] A. S. Yigit and A. P. Christoforou, "Coupled torsional and bending vibrations of drillstrings subject to impact with friction," Journal of Sound and Vibration, vol. 215, no. 1, pp. 167-181, 1998.

[9] A. Baumgart, "Stick-slip and bit-bounce of deep-hole drillstrings," Journal of Energy Resources Technology, vol. 122, no. 2, pp. 78-82, 2000.

[10] V. I. Gulyaev, P. Z. Lugovoi, V. V. Gaidaichuk, I. L. Solov'ev, and I. V. Gorbunovich, "Effect of the length of a rotating drillstring on the stability of its quasistatic equilibrium," International Applied Mechanics, vol. 43, no. 9, pp. 1017-1023, 2007.

[11] T. Richard, C. Germay, and E. Detournay, "A simplified model to explore the root cause of stick-slip vibrations in drilling systems with drag bits," Journal of Sound and Vibration, vol. 305, no. 3, pp. 432-456, 2007.

[12] Y. A. Khulief, F. A. Al-Sulaiman, and S. Bashmal, "Vibration analysis of drillstrings with string-borehole interaction," Proceedings of the Institution of Mechanical Engineers, Part C: Journal of Mechanical Engineering Science, vol. 222, no. 11, pp. 2099-2110, 2008. 
[13] M. F. Mahyari, M. Behzad, and G. R. Rashed, "Drill string instability reduction by optimum positioning of stabilizers," Proceedings of the Institution of Mechanical Engineers, Part C: Journal of Mechanical Engineering Science, vol. 224, no. 3, pp. 647-653, 2009.

[14] A. Ghasemloonia, D. G. Rideout, and S. D. Butt, "Vibration analysis of a drillstring in vibration-assisted rotary drilling: finite element modeling with analytical validation," Journal of Energy Resources Technology, vol. 135, no. 3, Article ID 032902, 2013.

[15] A. Ghasemloonia, D. Geoff Rideout, and S. D. Butt, "Analysis of multi-mode nonlinear coupled axial-transverse drillstring vibration in vibration assisted rotary drilling," Journal of Petroleum Science and Engineering, vol. 116, pp. 36-49, 2014.

[16] S. Dong, W. Zhang, H. Zhang et al., "Research on the distribution contact pressure between sucker rod and tubing string of rod pumping system in directional wells," Engineering Mechanics, vol. 28, no. 10, pp. 179-184, 2011.

[17] L.-m. Lao and H. Zhou, "Application and effect of buoyancy on sucker rod string dynamics," Journal of Petroleum Science and Engineering, vol. 146, pp. 264-271, 2016.

[18] S. A. Lukasiewicz, "Dynamic behavior of the sucker rod string in the inclined well," in Proceedings of the 1991 Production Operations Symposium, Oklahoma City, OK, USA, April 1991.

[19] J. Xu, "A new approach to the analysis of deviated rodpumped wells," in Proceedings of the 1994 SPE International Petroleum Conference \& Exhibition of Mexico, Veracruz, MX, USA, October 1994.

[20] J. Xu, D. R. Doty, and A. Shahraki, "A comprehensive rodpumping model and its application to vertical and deviated wells," in Proceedings of the 1999 SPE Mid-continent Operations Symposium, Oklahoma City, OK, USA, March 1999.

[21] W. Wang, Q. Di, J. Yao et al., "A new finite element method in analyzing mechanical properties of sucker rod strings in 3D directional wellbores," Acta Petrolei Sinica, vol. 31, no. 6, pp. 1018-1023, 2010.

[22] H. Wang and S. Dong, "Research on the coupled axialtransverse nonlinear vibration of sucker rod string in deviated wells," Journal of Vibration Engineering \& Technologies, 2020.

[23] S. Dong, Computer Simulation of Dynamic Parameters of Rod Pumping System Optimization, Petroleum Industry Press, Beijing, China, 2003.

[24] M. Xing and S. Dong, "A new simulation model for a beampumping system applied in energy saving and resourceconsumption reduction," SPE Production \& Operations, vol. 30, no. 2, pp. 130-140, 2015.

[25] X. Zhu, H. Tong, Q. Liu et al., "Research on the dynamic boundary condition between revolving drill string and borehole wall," China Mechanical Engineering, vol. 18, no. 15, pp. 1833-1837, 2018.

[26] X. Song and W. Li, "Crashworthiness numerical simulation of materical properties on vehicle steering mast," Journal of Chongqing Jiaotong University (Natural Science), vol. 31, no. 4, pp. 866-868, 2012. 